Türkiye Jeoloji Bülteni
Geological Bulletin of Turkey
$60(2017) 169-188$
http://tjb.jmo.org.tr

\title{
Bolvadin'de (Afyon-Akşehir Grabeni, Afyon) Gözlenen Yüzey Deformasyonlarının Jeolojik, Jeomorfolojik ve Jeodezik Analizi
}

Geologic, Geomorphologic and Geodetic Analyses of Surface Deformations Observed in Bolvadin (Afyon-Akşehir Graben, Afyon)

\section{Çağlar Özkaymak ${ }^{1,2 *}$, Hasan Sözbilir ${ }^{3,4}$, İbrahim Tiryakioğlu ${ }^{5,2}$, Tamer Baybura ${ }^{5}$}

\author{
${ }^{1}$ Afyon Kocatepe Üniversitesi, Jeoloji Mühendisliği Bölümü, 03200 Afyon \\ ${ }^{2}$ Afyon Kocatepe Üniversitesi, Deprem Uygulama ve Araştırma Merkezi, 03200 Afyon \\ ${ }^{3}$ Dokuz Eylül Üniversitesi, Jeoloji Mühendisliği Bölümü, 35160 İzmir \\ ${ }^{4}$ Dokuz Eylül Üniversitesi, Deprem Araştırma ve Uygulama Merkezi, 35160 İzmir \\ ${ }^{5}$ Afyon Kocatepe Üniversitesi, Harita Mühendisliği Bölümü, 03200 Afyon
}

Geliş/Received : 22.08.2016 • Düzeltilmiş Metin Geliş/Revised Manuscript Received : 03.10.2016 • Kabul/Accepted : 10.10 .2016 • Bask1/Printed : 01.04 .2017 Araştırma Makalesi/Research Article Türkiye Jeol. Bül. / Geol. Bull. Turkey

Öz: Batı Anadolu Genişleme Bölgesinde, son 10-20 yılda yıkıcı deprem olmaksızın oluşmuş ve oluşmaya devam eden yüzey deformasyonlarının belirgin örneklerinden biri, KB-GD uzanımlı Afyon-Akşehir Grabeni içerisinde yer alan Bolvadin yerleşim alanında gözlenmektedir. Bu alanda, bir kısmı imar planı içerisinde kalan bölge ile şehrin güneybatı kısmından başlayarak kuzeydoğu istikametine doğru yer alan bölgelerde, son 4 yıldan itibaren daha önceden olmayan bazı deformasyonlar oluşmuş ve oluşmaya devam etmektedir. Bölgede yapılan çalışmalarda, yıkıcı deprem olmaksızın, uzunlukları 300 metre ile $2 \mathrm{~km}$; doğrultuları ise $\mathrm{K} 15^{\circ} \mathrm{D}$ ile $\mathrm{K} 70^{\circ} \mathrm{D}$ arasında değişen hareketler ve yarılmalar şeklinde gelişen kademeli yüzey deformasyonları haritalanmıştır. Yerleşim alanı içerisinde haritalanan yüzey deformasyonlarının en kuzeyde olanı Bolvadin Fayı'nın güneybatıdaki devamı niteliğindedir. Yapılan jeolojik ve jeomorfolojik analizler yüzey faylanmaları boyunca, güneydoğuda yer alan bloğun 10-40 cm arasında düştügüne ișaret etmektedir. Yapılan jeodezik analizler bölgedeki son dört yıllık düşey yerdeğiștirme hızının $7,1 \mathrm{~cm} / \mathrm{y} 11$ olduğunu göstermektedir. Bu sonuçlar, Bolvadin Fayı boyunca gelişen yüzey deformasyonlarının önemli bir nedeninin, yeraltı su seviyesi düşüşüyle ilgili olduğunu göstermektedir. Söz konusu yüzey deformasyonlarının oluşumuna, bölge tektoniğinin katkısını ortaya koymak için hendek tabanlı paleosismolojik çalıșmalara ihtiyaç vardır.

Anahtar Kelimeler: aktif tektonik, asismik yüzey deformasyonu, Batı Anadolu, Bolvadin.

\begin{abstract}
One of the prominent examples of the surface deformations that have been formed without destructive earthquake failure since last 10-20 years in the west Anatolian extensional province, observed in Bolvadin settlement area located at the middle part of the Afyon-Akssehir Graben. In this area, some linear surface deformations that starts on the southwestern side of the town and can be followed until the northwestern side have been observed since last 4 years. During the field studies in Bolvadin area, progressive surface deformations such as surface faults and earth fissures whose length varies between 300 meters and 2 kilometers and strike varies between $N 15^{\circ} \mathrm{E}$ and $N 70^{\circ} \mathrm{E}$ are mapped. The northernmost one of the surface deformations mapped in settlement area of Bolvadin have the characteristics of the southwestern continuation of Bolvadin Fault. Besides this, qeologic and morphological analysis indicate that the southeastern block is a down-dropped block and vertical displacements along the deformation zone are varies between 10-40 cm. According to geodesic data, measured rates of vertical offset in the Bolvadin is $7.1 \mathrm{~cm} /$ year. In order to find out the effect of active tectonism on formation of surface deformations, further trench based palaeosismological studies are necessary.
\end{abstract}

Key Words: Active tectonics, aseismic surface deformations, Bolvadin, western Anatolia. 


\section{GíRiş}

Asismik yüzey deformasyonları (AYD), genellikle insan aktiviteleri sonucu yeraltı su seviyesinin düşmesi sonucu yüzey altındaki konsolide olmayan sedimanların sıkışmasına bağlı olarak gelişen oturma ilişkili deformasyonlar olarak tanımlanır (Holzer, 1984; Pewe, 1990; Koca vd. 2011; Hernández-Madrigal vd. 2014). Yüzey yarıları ve/veya yüzey faylanması şeklinde gelişen bu deformasyonlar özellikle yerleşim alanlarında, su/doğalgaz boruları, kanalizasyon sistemleri, gömülü boru hatları gibi yüzey altında, ve binalar, duvarlar, su kanalları, karayolu, demiryolu gibi yüzeyde yer alan insan yapımı kültürel eserler ve tesislere ciddi hasarlar vermektedir. Gelişen bu yüzey yarıkları genişleme gerilmesi ile ilişkilidir ve yarık düzlemine dik yönlü açılma geometrisine sahiptirler. Yeraltı su seviyesinin düşmesine bağlı olarak gelişen yüzey faylanmaları ise, o bölgede daha önceden varolan faylar boyunca meydana gelirler (Van Siclen, 1967; Holzer, 1980). AYD meydana gelen bölgelerde yapılan bazı hidrojeolojik çalışmalar, bölgede yer alan fayların yeraltı suları için bir bariyer niteliğinde olduğu; özellikle normal fayların her iki bloğundaki su seviyelerinin fayın ayırdığı bloklarda değişiklik gösterdiği saptanmıştır(Holzer, 1978, Pankratz vd. 1978; Koca vd. 2011). Benzer şekilde genellikle fayların her iki bloğundaki oturmaları denetleyen kayaç litolojisi aynı değildir ve bu alanlarda farklı yaşa/dayanıma sahip kayaç topluluklarının tektonik olarak yanyana gelmesi beklenir.

Aktif grabenler boyunca konsolide olmamış, genç alüvyal, fluvial, gölsel çökellerin ve bu çökelleri denetleyen aktif normal fayların baskın olduğu Batı Anadolu Genişleme Bölgesi (BAGB), AYD gelişimi bakımından dünyanın en uygun alanlarından birisidir. BAGB içerisinde yer alan, Karaağaçl1-Yeniköy, Sarıgöl-Manisa (Gediz Grabeni), Ödemiş, Bayındır-İzmir (Küçük Menderes Grabeni), Germencik, Söke-Aydın
(Büyük Menderes Grabeni), Yassıüme-Burdur (Burdur Grabeni), Kınık-Dinar-Afyon (Gülovas1 Grabeni), Eber, Deresinek, Çobanlar ve BolvadinAfyon (Afyon-Akşehir Grabeni) bölgelerinde son 20 yıldır yıkıcı deprem olmaksızın gelişen yüzey deformasyonlarının varlığı rapor edilmiştir (Şekil 1) (Gürsoy vd. 1997; Demirtaş vd. 2008a; Koca vd. 2011; Özkaymak vd. 2014 ve 2015). Bu alanlardan birisi olan Sarıöl (Manisa) yerleşim alanı, 1969 depreminin (M:6.8) yüzey kırı̆̆1 oluşturduğu Gediz Grabeni'nin güneydoğu ucunda, grabenin güney kenar faylarından birisi olan Sarıöl Fay1 üzerinde yer alır (Şekil 1). Bu fay boyunca gözlenen güncel yüzey deformasyonlarının nedenleri, Koca vd. (2011) tarafindan yapılan bir çalışmada jeolojik haritalama, morfometrik ölçümler, karotlu zemin sondaj1, konsolidasyon deneyleri gibi yöntemler kullanılarak detaylı olarak yorumlanmıştır. Batı Anadolu'da gözlenen asismik yüzey deformasyonlarının en güncel örnekleri, kuzeybatı-güneydoğu gidişli çok sayıda aktif normal fay segmentlerinden oluşan AkşehirSimav Fay Sistemi'nin (ASFS) güneydoğu devamında yer alan Afyon-Akşehir Grabeni içerisinde gözlenmektedir. Bu alan, BAGB'nin en önemli sismojenik kuşaklardan birisidir. Grabenin kuzey kenar faylarından birisi olan Bolvadin Fay1 boyunca meydana gelen güncel yüzey deformasyonları, aynı zamanda graben içerisinde meydana gelen en son yıkıcı ve yüzey kırığ oluşturan depremlerin episantırlarının (03 Şubat 2002 Çay Depremleri, Mw: 6.3 ve 6.0) hemen kuzeyinde yer alır.

$\mathrm{Bu}$ çalışma, Bolvadin'de (Afyon-Akşehir Grabeni, Afyon) gözlenen asismik yüzey deformasyonlarının haritalanması, jeolojik, jeomorfolojik ve jeodezik yöntemler kullanılarak analiz edilmesini ve Sarıöl'de (Gediz Grabeni, Manisa) gözlenen yüzey deformasyonları ile oluşum ve kökensel açıdan karşılaştırılmasını konu almaktadir. 


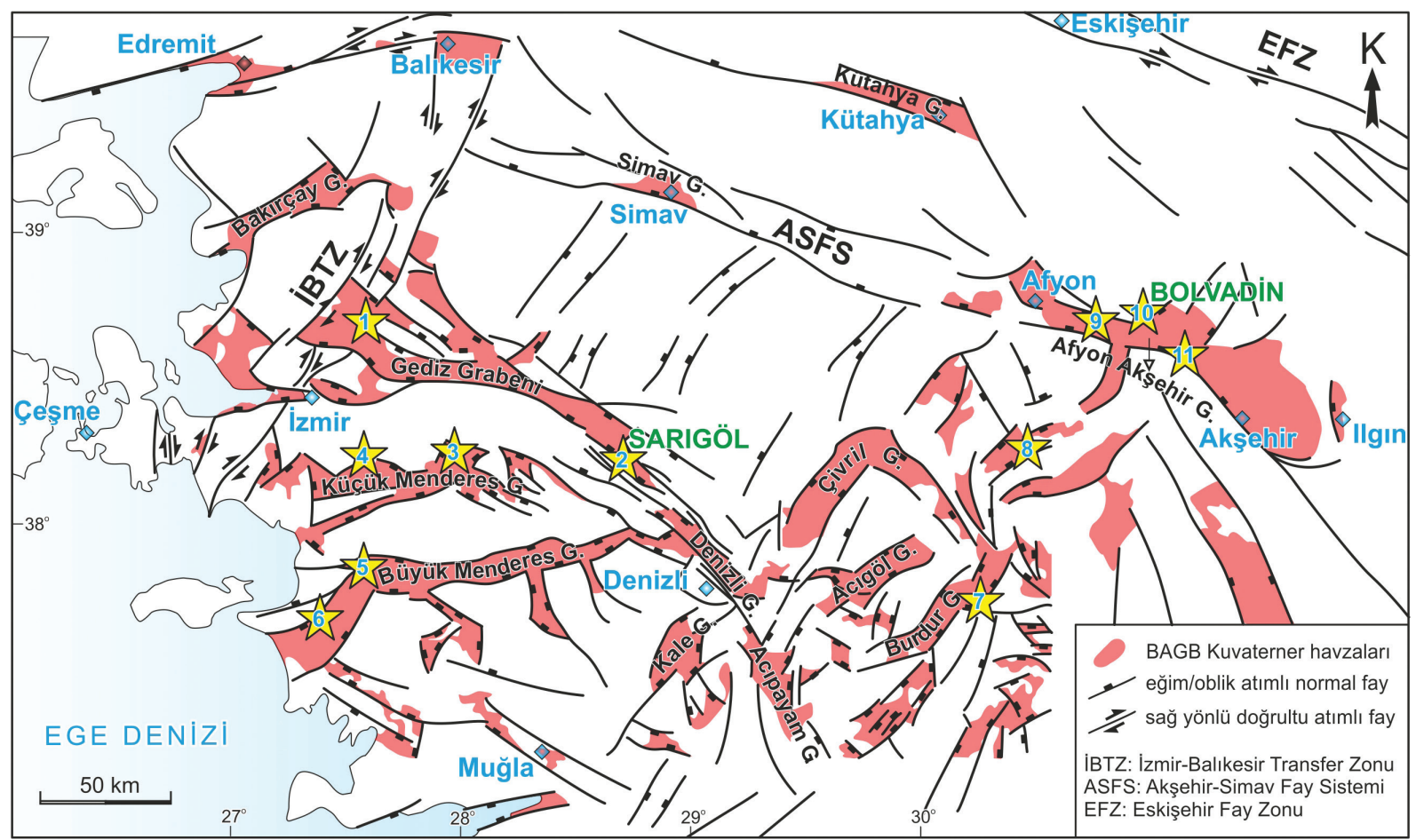

Şekil 1. Batı Anadolu Genişleme Bölgesi’nin (BAGB) ana neotektonik yapılarını ve aktif havzalarını gösteren basitleştirilmiş harita (Kaymakçı, 2006, Emre vd. 2011; Özkaymak vd. 2013 ve Özkaymak, 2015'den düzenlenmiş̧ir). Sarı dolgulu yıldızlar, BAGB içerisindeki Asismik Yüzey Deformasyonları (AYD) lokasyonlarını göstermektedir; 1: Karaağaçl1-Yeniköy, 2: Sarıg̈̈l-Manisa (Gediz Grabeni), 3: Ödemiş, 4: Bayındır-İzmir (Küęük Menderes Grabeni), 5: Germencik, 6: Söke-Aydın (Büyük Menderes Grabeni), 7: Yassıgüme-Burdur (Burdur Grabeni), 8: Kınık-DinarAfyon (Gül Ovası Grabeni), 9: Çobanlar, Eber-Deresinek, ve Bolvadin-Afyon (Afyon-Akşehir Grabeni (AAG)).

Figure 1. Simplified neotectonic map showing the major active basins in West Anatolian Extensional Province (WAEP) (compiled from Kaymakçı, 2006, Emre et al., 2011; Özkaymak et al. 2013 and Özkaymak, 2015). Yellow filled stars show the locations of aseismic surface deformations in WEAP; 1.Karaağaçlt-Yeniköy, 2. Sarıgöl-Manisa (Gediz Graben); 3. Ödemiş, 4. Bayındır-İzmir (Küçük Menderes Graben); 5. Germencik, 6. Söke-Aydın (Büyük Menderes Graben); 7. Yassıüme-Burdur (Burdur Graben); 8. Kınık-Dinar-Afyon (Gül Ovası Graben), 9. Çobanlar, Eber-Deresinek, and Bolvadin-Afyon (Afyon-Akşehir Graben (AAG)).

\section{AFYON-AKŞEHİR GRABENI}

ASFS'nin güneydoğu kesiminde yer alan Afyon-Akşehir grabeni (AAG), kuzeydoğuda yer alan Orta Anadolu ile güneybatıda yeralan Isparta açısını (Blumenthal, 1963) birbirinden ayıran, yaklaşık 4-20 km genişliğinde, $130 \mathrm{~km}$ uzunluğunda olan, KB-GD uzanımlı, aktif olarak büyüyen bir kıtasal rift alanıdır (Koçyiğit, 1984, Koçyiğit vd. 2000; Koçyiğit ve Özacar, 2003). AAG'ni kuzeyden ve güneyden sinırlayan faylar tipik olarak Pliyo-Kuvaterner öncesi yaşlı temel kayalar ile Pliyo-Kuvaterner yaşlı modern havza dolgusu arasındaki yapısal dokanağ1 temsil ederler (Şekil 2). Grabenin kenar fayları, 2011 y1lında güncellenen Türkiye Diri Fay Haritasında diri fay sınıfında değerlendirilmiştir (Emre vd. 2011). Afyon yerleşim alanı doğusunda, kuzey sınır faylarından birisi olan Çobanlar Fay Zonu (ÇFZ) yaklaşık $30 \mathrm{~km}$ uzunluğundadır. Batıda Akcın doğusundan başlar ve Çavdarlı, Çobanlar Hamidiye üzerinden Bolvadin batısına kadar 
BKB-DGD doğrultusu boyunca izlenebilir. Fayın gidişi özellikle Akçın ile Çobanlar arasında çizigiseldir (Şekil 2). Zon boyunca çok sayıda iyi korunmuş fay düzlemleri zonun eğim atımlı normal karakterine ait izler taşır. Afyon Akşehir Grabeni'ni güneyden sınırlayan Işıklar Fay Zonu (IsFZ) ise genel olarak BKB-DGD uzanımlı olup K-KKD'ya eğimli birbirine paralel/yarıparalel ve grabene doğru basamaklı bir geometri oluşturan fay kollarından oluşur (Şekil 2). Batıda Afyonkarahisar yerleşim alanı güneyinde yeralan Büyük Kalecik'ten başlayarak doğuya doğru Halimoru, Nuribey üzerinden Işılara doğru ilerleyen ve doğuda Gözsüzlü ve Heybeli kaplıcasına kadar yaklaşık $35 \mathrm{~km}$ boyunca takip edilen normal/oblik atımlı fay kollarından oluşur.

Afyon Akşehir Grabeni'nin Karamık Grabeni ile çakıştığı alandan itibaren daha doğuda yeralan Sultandağı Fayı baskın olarak Neojen öncesi metamorfik kayaçlar ile genç alüvyal kolüvyal ve flüvyal çökeller arasındaki keskin sınırı oluşturur (Şekil 2). Sultandağı Fayı yaklaşık $90 \mathrm{~km}$ uzunluğunda eğim atımlı normal faydır. Batıda Çay ile doğuda Doğanhisar arasında çizgisel bir gidiş sunan morfolojik olarak belirgin sarplıklar boyunca takip edilebilir, dağ önü boyunca iyi gelişmiş alüvyal yelpazeler tipiktir. Grabenin kuzeydoğusunda yer alan kuzey kenar fayları, en-eşelon dizilimlidirler ve batıdan doğuya doğru Bolvadin Fayı (BF), Büyük Karadağ Fayı (BkF), Çukurcak Fayı (ÇuF) gibi KD-GB uzanımlı eğim atımlı normal faylar ile temsil edilirler.

Afyon-Akşehir Grabeni ve çevresinde yüzlek veren kayaçlar başlıca üç grup altında toplanmaktadır; (1) Neojen öncesi Afyon Zonu, (2) Neojen birimleri ve (3) Pliyo-Kuvaterner yaşlı modern graben dolgusu (Şekil 2 ve 3). Afyon Zonu, kuzeyindeki Tavşanlı Mavişist Zonu, güneyindeki Menderes Masifi ve Likya Naplarına ait kayaçlar, batıda ise Bornova Filiş
Zonuna ait kayaçlar ile tektonik olarak sınırlanır (Okay ve Tüysüz, 1999; Bozkurt ve Oberhansl1, 2001). Afyon Zonu kayaları başlıca, Jura öncesi (Silüriyen-Geç Triyas zaman aralığı) oluşmuş düşük dereceli metamorfitler, Jura-Erken Kretase yaşlı platform karbonatları, Kretase yaşlı bazikultrabazik tektonik kaya dilimleri (başlıca peridotit, serpantinit, gabro), Geç Kretase yaşlı ofiyolitik karışık (melanj), Eosen yaşlı filiş ile volkanitler ve Oligosen yaşlı orojenik molas (sığsu ve akarsu ortamında oluşmuş kalın sedimanter istif) ile temsil edilir (Okay vd. 1996).

Afyon Akşehir Grabeni çevresinde yüzlek veren Neojen yaşlı birimler, genel olarak, kalınlıkları 0,5-2 km arasında değişen iki istif ile temsil edilir; (1) Akarsu ve göl ortamlarında oluşmuş, yer yer ekonomik düzeyde kömür içeren sedimanter bir istif, (2) Alt ve orta düzeylerde kalk-alkali üste doğru egemen olarak alkali özellikler taşıyan volkanitlerdir (Şekil 2 ve 3) (Afyon Volkanitleri) (Çevikbaş vd. 1988; Aydar vd. 2003; Kibici vd., 2012). Neojen istifi, en altta yaşlı temel kayalardan türemiş çok tane bileşenli ve kötü boylanmalı bir taban çakıltaşı ile başlar ve yukarıya doğru kumtaş1, çamurtaş1-kiltaş1-marn ve ilk volkanizmanın verisi olan tüf ve kömür aradüzeyleriyle devam eder. $\mathrm{Bu}$ taban istifi daha üste doğru yer yer derin gölsel sedimanlara (organik maddece zengin şeyl ve gölsel kireçtaşı ardaşımı) geçiş gösterir, yer yer de kalın bir volkanik kayaç topluluğu tarafından uyumlu olarak örtülür. Her iki istif birbirleriyle yanal-düşey geçişli dokanak ilişkisi sunar (Şekil 3).

Geç Pliyosen-Kuvaterner yaşlı istif ise, modern graben dolgusu birimleri ile temsil edilir. İstif iki ana fasiyesten oluşur; (1) İri taneli kenar fasiyesi (Alüvyal yelpaze, kolüvyal sedimanlar/ yamaç döküntüleri) (2) İnce taneli graben ortası fasiyesi (Alüvyal yelpazelerin uç kesimleri ve Akarsu tortulları) (Şekil 2 ve 3). 


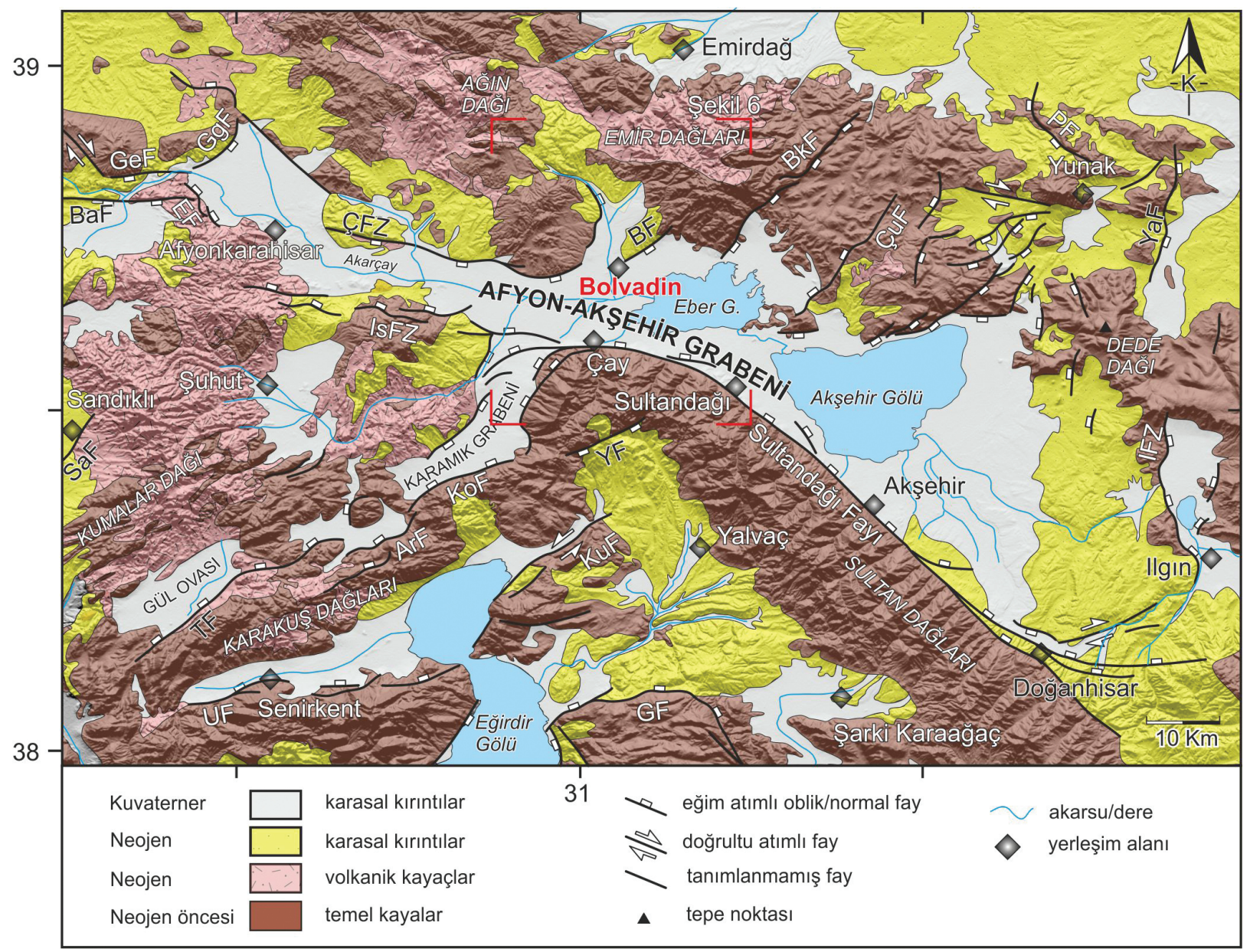

Şekil 2.Afyon-Akşehir Grabeni ve yakın çevresinin jeoloji haritası (Emre vd. 2011 ve Turan, 2002'den düzenlenmiş̧ir). Kısaltmalar: BaF: Balmahmut Fayı; GgF: Gazlıgöl Fayı; EF: Erkmen Fayı; ÇFZ: Çobanlar Fay Zonu; IsFZ: Işılklar Fay Zonu; BF: Bolvadin Fayı; BkF: Büyük Karabağ Fayı; ÇuF; Çukurcak Fayı; PF: Piribeyli Fayı; YaF: Yavaşlı Fayı; IFZ: Ilgın Fay Zonu; YF: Yarıkkaya Fayı; KuF: Kumdanlı Fayı; GeF: Gecek Fayı, GF: Gelendost Fayı; KoF: Koçbeyli Fayı; ArF: Arızlı Fayı; UF: Uluborlu Fayı; TF: Tatarlı Fayı; SaF: Sandıklı Fayı.

Figure 2. Simplified Geologic map showing the Afyon-Akşehir Graben and nearby area (compiled from Emre et al. 2011 and Turan, 2002). Abbreviations: BaF: Balmahmut Fault; GgF: Gazlıgöl Fault; EF: Erkmen Fault; ÇFZ: Çobanlar Fault Zone; IsFZ: Işılklar Fault Zone; BF: Bolvadin Fault; BkF: Büyük Karabă̆ Fault; ÇuF; Çukurcak Fault; PF: Piribeyli Fault; YaF: Yavaşlı Fault; IFZ: Ilgın Fault Zone; YF: Yarlkkaya Fault; KuF: Kumdanl Fault; GeF: Gecek Fault, GF: Gelendost Fault; KoF: Koçbeyli Fault; ArF: Arızlı Fault; UF: Uluborlu Fault; TF: Tatarl Fault; SaF: Sandıklı Fault. 


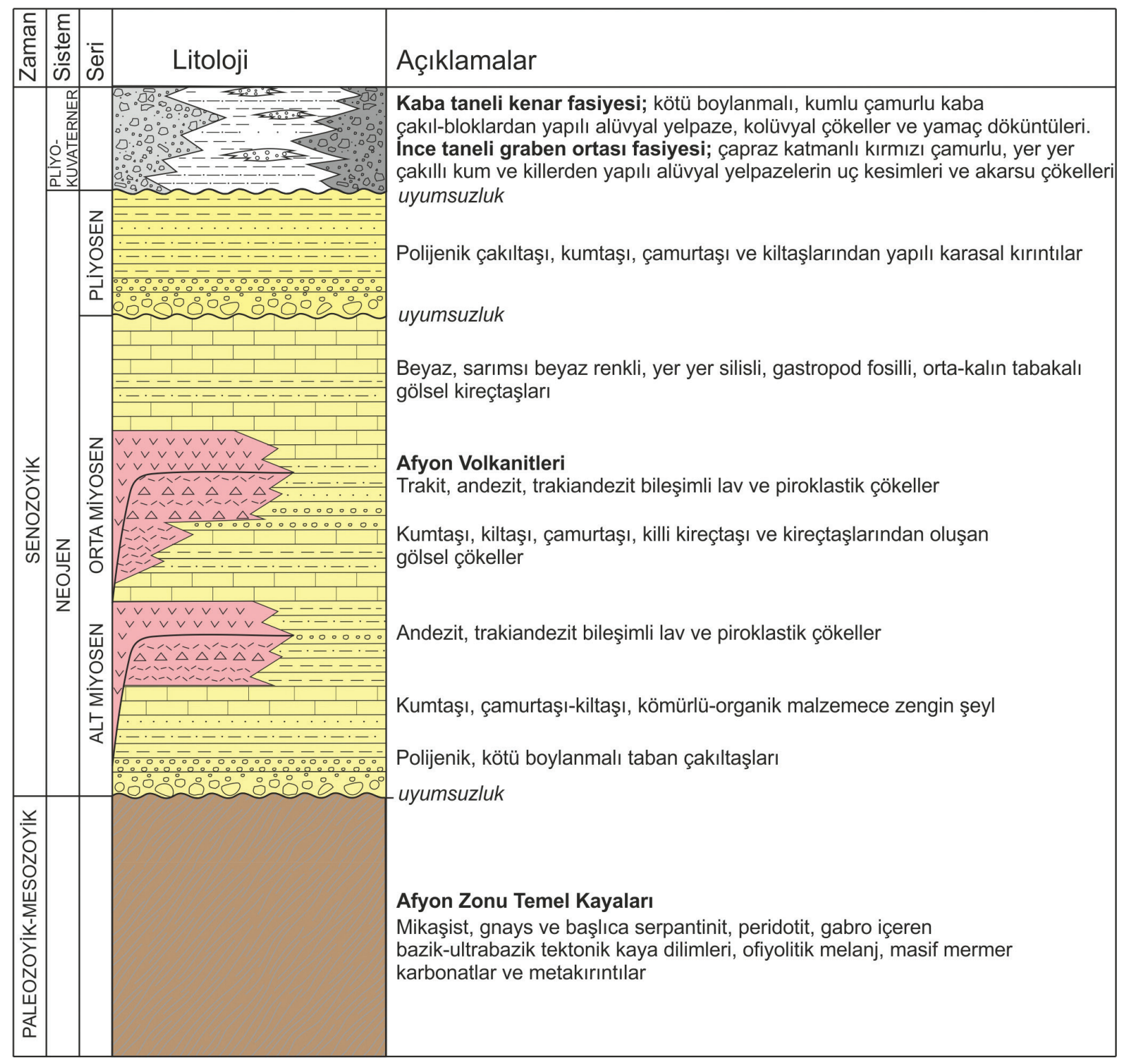

Şekil 3. Afyon-Akşehir Grabeni ve yakın çevresinin genelleştirilmiş stratigrafik kolon kesiti

Figure 3. Generalised lithostratigraphic columnar section of the Afyon-Akşehir Graben

\section{BOLVADIN VE YAKIN ÇEVRESININ SISMOTEKTONIK ÖZELLIKLLRİ}

Afyon Akşehir Grabeni ve yakın çevresi, sismik açıdan oldukça aktif bir yap1 göstermektedir. Şekil 4'te verilen bölgede aletsel dönem boyunca büyüklükleri 4 ile 7.2 arasında değişen 267 adet deprem meydana gelmiştir (KOERİ, 2016). 1995 ve sonrasinda meydana gelen bazı depremlerin odak mekanizma sonuçlarına göre, bölgede yeralan faylar, doğrultu atımı ve eğim atımlı normal faylanma karakterinde çalışmakta ve deprem üretmektedir (Şekil 4). Bununla beraber, Afyon Akşehir Grabeni boyunca 2000 yılından sonra büyüklükleri 2 ile 4 arasında değișen yaklaşık 2000 adet deprem meydana gelmiştir (KOERİ, 2016). 


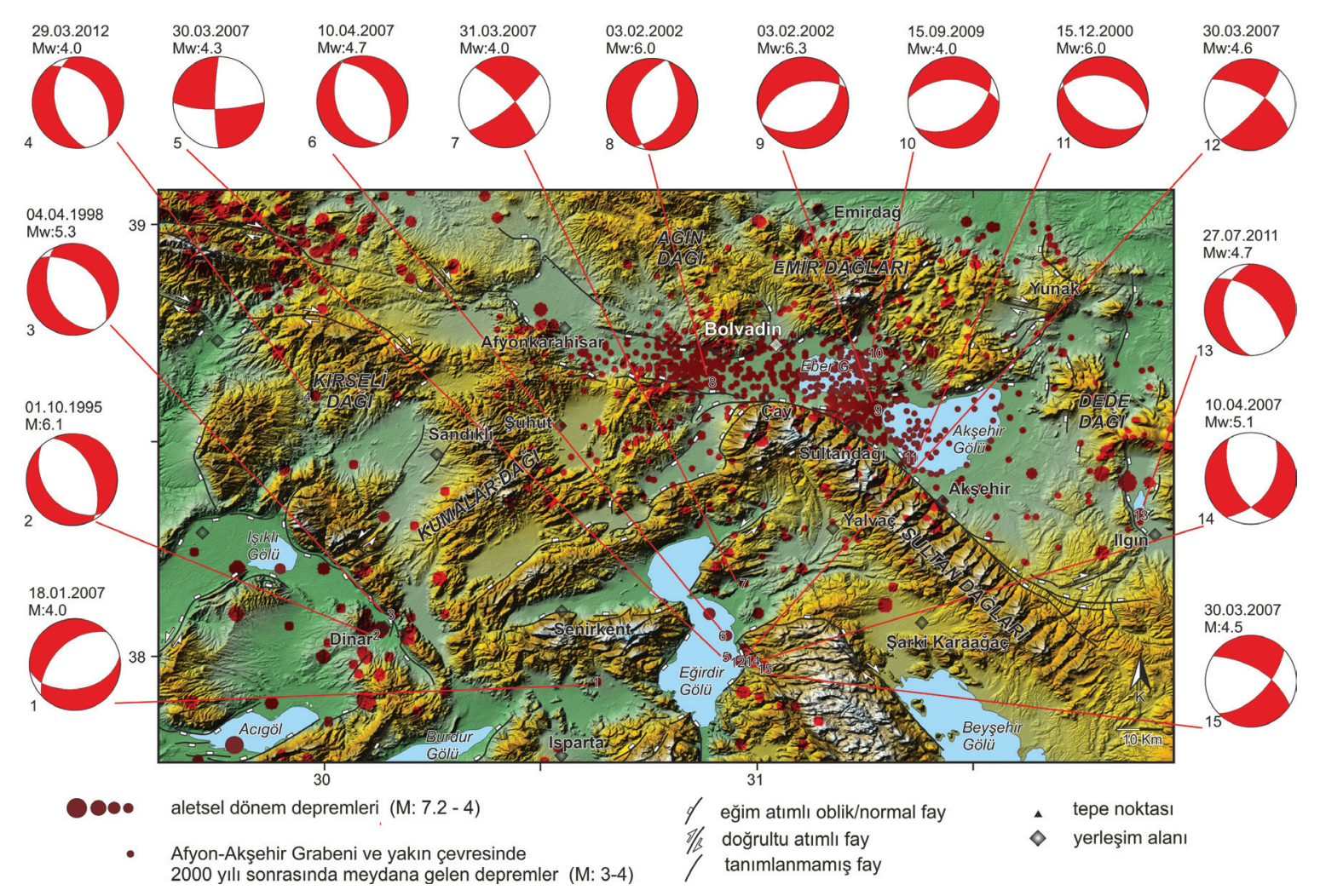

Şekil 4. Afyon-Akşehir Grabeni ve yakın çevresinin sismotektonik haritası (Faylar Emre vd. 2011'den; Odak Mekanizma Çözümleri, EMSC, 2016'dan; Afyon-Akşehir Grabeni içerisinde 2000 yılından sonra meydana gelen (M:3-4) depremler KANDİLLİ, 2016'dan alınmıştır).

Figure 4. Seismotectonic map of the Afyon-Akssehir Graben (Faults are taken from Emre et al. 2011; Fault plane solutions are taken from EMSC, 2016; earthquakes data (M:3-4) occurred in Afyon-Akşehir Graben are taken from KANDILLİ, 2016). For abbreviations, see Figure 2.

Afyon-Akşehir Grabeni içerisinde, 1911 y1lında meydana gelen ve Bolvadin ve Çay'da etkili olan deprem ile Heybeli Kaplicasinda sicak su çıkmaya başladığı belirtilmektedir (Pınar ve Lahn, 1952). Tarihsel dönem kayitlara göre bu depremin şiddeti VIII'dir (Ergin vd. 1967). Sonraki yıllarda Afyon-Akşehir grabeni içerisinde meydana gelen orta büyüklükteki aletsel dönem depremlerin zaman ve dışmerkez dağılımları, Sultandağı Fayı üzerinde güneydoğudan kuzeybatıya doğru bir deprem göçünün varlığını ortaya çıkarmıştır (Şekil 5) (Demirtaş vd. 2002; Emre vd. 2003; Tiryakioğlu vd. 2015). Sultandağı Fayı'nın doğusunda, 1921'de Argitanl1-Akşehir depremi (M:5.9) ile başlayan, 1946'da Argitanl1-Akşehir arasında (5.7), 2000 yılında ise Sultandağı güneydoğusunda (Mw:6.0) etkili olan sismik hareketlilik son olarak 3 Şubat 2002'de Sultandağ1 ve Çay bölgelerinde yüzey kırığ1 oluşturmuştur. 2000 ve sonraki yıllarda meydana gelen bazı depremlerin odak mekanizma çözümleri Afyon Akşehir Grabeninin orta ve doğu bölümlerinde KD-GB ve KB-GD yönlü bimodal genişlemenin varlığına işaret etmektedir (Şekil 5). 3 Şubat 2002 tarihinde meydana gelen Çay depremleri ise, Çay ile Sultandağı arasında ve Çay batısında $30 \mathrm{~cm}$ 'e varan düşey yerdeğiştirmeye sahip yaklaşık 26 km uzunluğunda yüzey kırığ1 oluşturmuştur (Emre vd. 2003; Akyüz vd. 2006). 3 Şubat tarihinde meydana gelen ilk deprem (Mw: 6.3) Eber Gölü güneyinde saat 09:11'de meydana gelmiştir. $\mathrm{Bu}$ deprem ile Sultandağı Fayının batısında, Eber Güneyi, Yeşilyurt Mahallesi, Çay 
ilçe merkezi, Cumhuriyet ve Maltepe mahalleleri arasında yaklaşık D-B doğrultulu kuzeye eğimli ve kuzeyde kalan bloğu düşüren yüzey kırıkları oluşmuştur (Şekil 6). İkinci deprem (Mw: 6.0) ise, 11:26'da Çay batısında meydana gelmiştir. Bu depremle Kadıköy ve Maltepe mahalleleri yakın civarında K20D uzanımlı ve güneydoğuya eğimli yüzey kırıkları oluşmuştur (Şekil 6) ve kırığın doğusunda kalan blokta $10 \mathrm{~cm}$ 'e kadar düşmeler gözlenmiştir (Özden vd. 2002). Bu depremlerin odak mekanizma çözümleri de arazi verilerini destekler bir şekilde, her iki depremi üreten fayın da eğim atımlı normal karakterde çalıştığını; ilk depremin DKD-BGB; ikinci depremin ise KKD-GGB doğrultulu fayların kırılması sonucu geliştiğini göstermektedir (Şekil 6). 3 Şubat Çay depremlerinden sonra bölgede çalışma yapan araştırmacılar (Demirtaş vd. 2002; Koçyiğit vd. 2002; Özden vd. 2002; Emre vd. 2003; Yürür vd. 2003; Ulusay vd. 2004; Akyüz vd. 2006), ilk depremin Sultandağı Fayı üzerinde meydana geldiği konusunda hemfikir iken, KKD-GGB uzanımlı yüzey kırığı oluşturan ikinci depremin hangi fay üzerinde meydana geldiği tartışma konusu olmuştur. Bazı araştırmacılar (Koçyiğit vd. 2002; Akyüz vd. 2006), her iki depremin de Sultandağı Fayı üzerinde geliştiğini ifade ederken, Emre vd. (2003)'e göre ikinci deprem KD-GB uzanımlı Kali Çayı segmenti üzerinde yüzey kırığı oluşturmuştur. Demirtaş vd. (2002) ise, ikinci depremin Akşehir ile Eber Gölleri arasından geçen KD-GB uzanımlı Üçkuyu Fayı üzerinde meydana geldiğini ileri sürmüştür. Özden vd. (2002), ikinci depremin, ilk depremde oluşan yüzey kırıklarına yaklaşık dik olan farklı bir normal fay üzerinde meydana geldiğini ifade etmiştir.

Son depremlerden sonra, bu deprem göçünün KB'ya doğru mu devam edeceği yoksa Sultandağ fayı ile sınırlı mı kalacağı? Ya da farklı bir doğrultuda mı devam edeceği? soruları bir çok araştırmacı tarafından tartışılmıştır ve yakın gelecekte fayın Çay'ın batısında kalan parçasında yüksek sismik riske dikkat çekmişlerdir (Özden vd. 2002; Emre vd. 2003; Yürür vd. 2003; Ulusay vd. 2004; Akyüz vd. 2006).

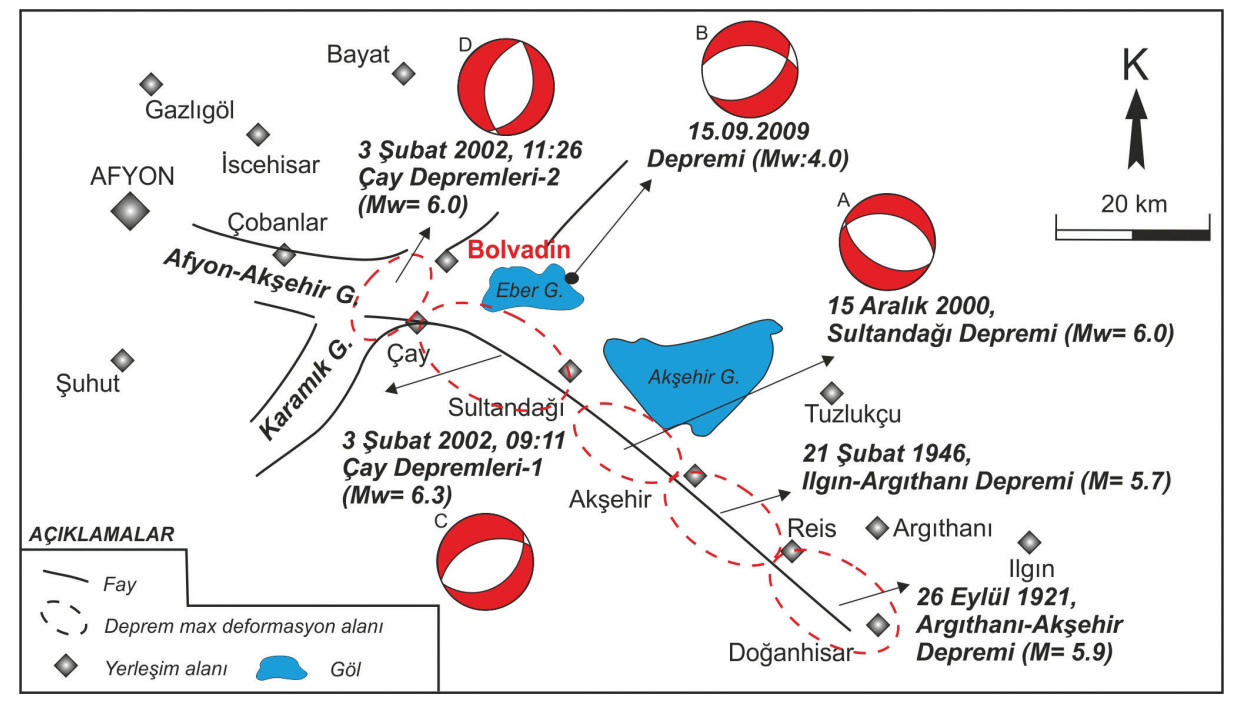

Şekil 5. Sultandağı Fayı boyunca son yüzyılda meydana gelen yıkıcı depremlerin güneydoğudan kuzeybatıya doğru zaman içerisindeki göçünü gösteren harita (Demirtaş vd. 2002; Tiryakioğlu vd. 2015'den değiştirilmiştir; odak meknizma çözümleri EMSC, 2016'dan alınmıştır).

Figure 5. The map showing northwestward trends of earthquake migration along the Sultandağ Fault during the last century (compiled from Demirtaş et al. 2002; Tiryakioğlu et al. 2015). 


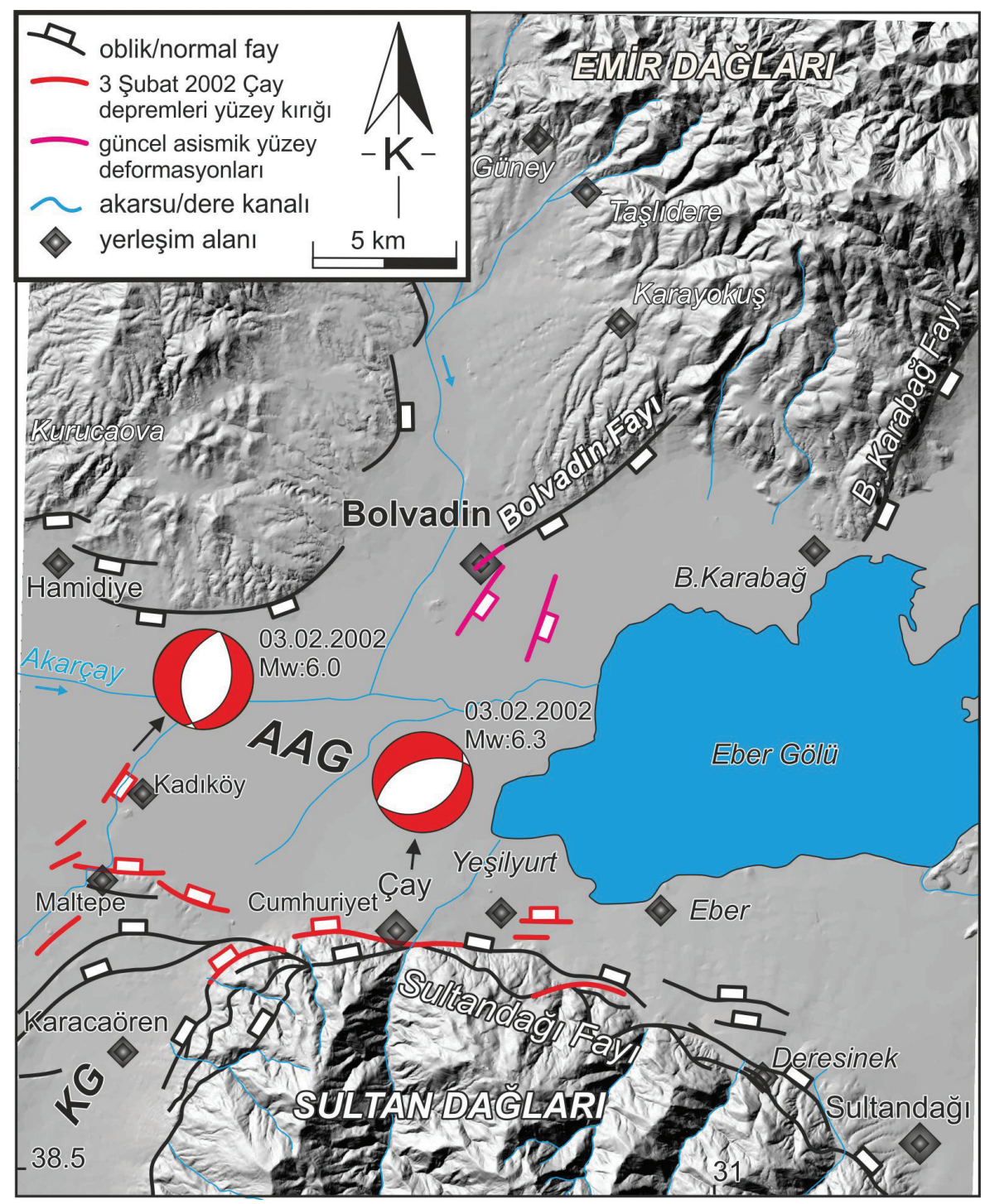

Şekil 6. Bolvadin ve yakın civarının diri fay haritası (Yüzey kırığı ve faylar Emre vd. 2011'den alınmıştır). Kısaltmalar: AAG: Afyon-Akșehir Grabeni, KG: Karamık Grabeni.

Figure 6. Active fault map of Bolvadin and nearby area (Surface ruptures of 3 February 2001 earthquakes and active faults are taken from Emre et al. 2011). Abbreviations: AAG: Afyon-Akşehir Graben, KG: Karamık Graben.

\section{BOLVADİN FAYI}

3 Şubat 2002 yılında meydana gelen depremler ile aktif çöküntü alanı olduğu belgelenen Eber Gölü'nün yeraldığı graben tabanını kuzeyden sınırlayan kenar faylarından birisi olan Bolvadin Fayı, yaklaşık $10 \mathrm{~km}$ uzunluğunda, KD-GB uzanımlı aktif bir faydır. Kuzeydoğusu boyunca morfolojik olarak belirgin çizgisellik sunan fay (Şekil $7 \mathrm{a}$ ve b), güneybatısında alüvyon zemin üzerine kurulu olan Bolvadin yerleşim alanı içerisine girer ve bu noktadan itibaren takip edilemez. Fay düzlemleri üzerindeki kinematik göstergeler, fayın eğim atımlı normal fay karakterine işaret etmektedir. Bolvadin Fay düzlemi üzerindeki eğim atımlı normal faylanma ilişkili kayma yüzeyi fay çiziği seti (Şekil 7 c 

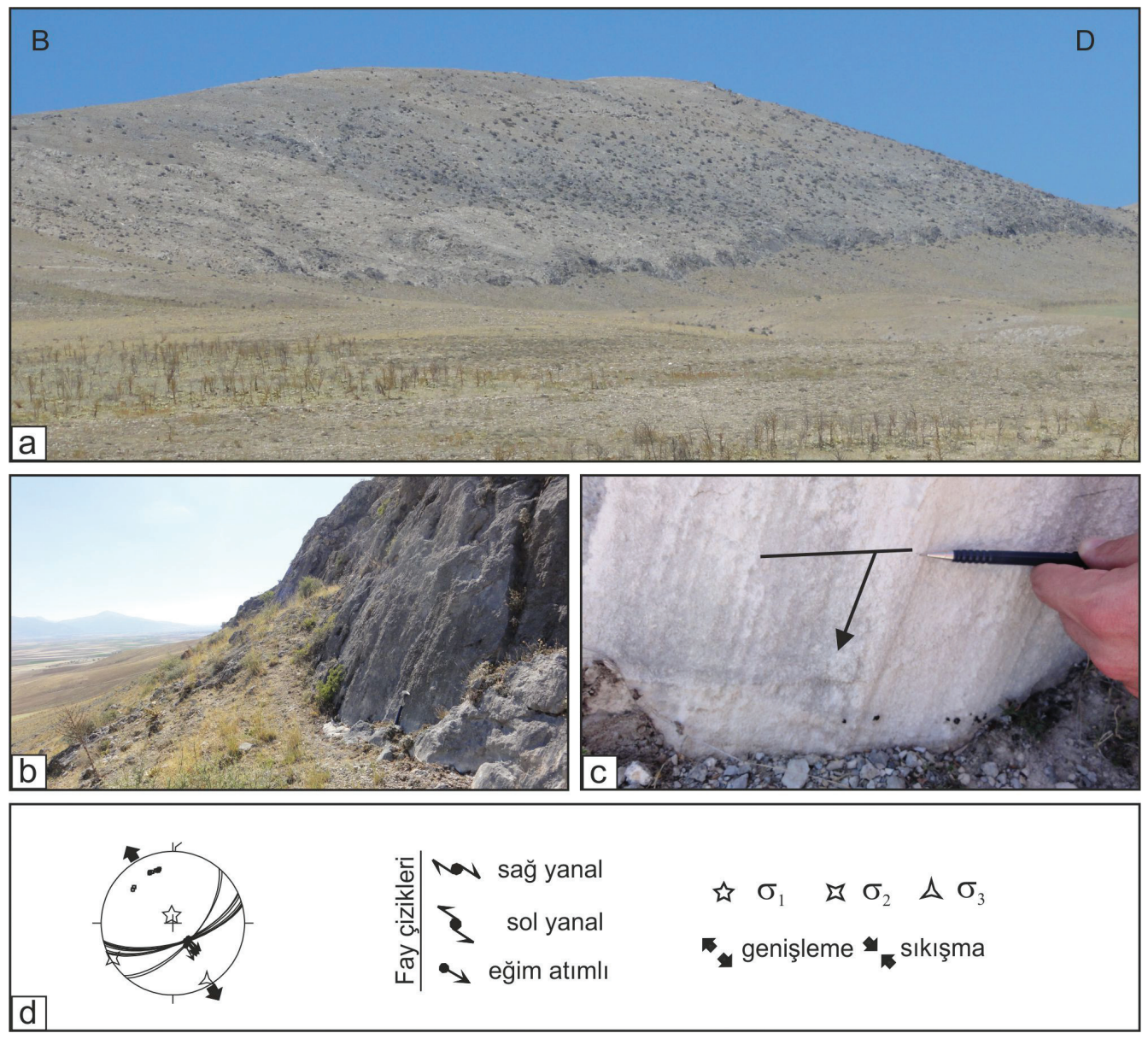

Şekil 7. Bolvadin master fayının a) panoramik görüntüsü b) fay düzlemleri c) fay çiziklerini gösteren arazi fotoğrafları d) kayma yüzeyi kinematik ölçümlerine göre yapılan paleostres analizi.

Figure 7. a) Panoramic view, b) Fault planes, c) Faults stries d) Paleostress analyses of Bolvadin master fault.

ve d) ile hesaplanan sonuçlara göre asal gerilim eksenleri $(\sigma 1, \sigma 2$ ve $\sigma 3)$ sirasiyla $351^{\circ} / 81^{\circ}$, $240^{\circ} / 03^{\circ}, 149^{\circ} / 09^{\circ}$ (yönlem/dalım) olarak elde edilmiştir. Hesaplanan değerler Bolvadin Fayı üzerinde etkili olan gerilme rejiminin KB-GD yönlü saf genişleme şeklinde olduğuna işaret etmektedir.

\section{BOLVADIN'DE GÖZLENEN YÜZEY DEFORMASYONLARININ JEOLOJIKK ANALIZİ}

Genel olarak alüvyon zemin üzerinde yer alan Bolvadin yerleşim alanı merkezinde, birkısmı imar planı içerisinde kalan bölge ile şehrin güneybatı kısmından başlayarak kuzeydoğu istikametine doğru yer alan bölgelerde, son 4 y1ldan itibaren daha önceden olmayan bazı deformasyonların oluştuğu ve oluşmaya devam ettiği gözlenmiştir (Şekil 8). Bölgede yapılan çalışmalarda, yıkıcı deprem olmaksızın, uzunlukları 300 metre ile $2 \mathrm{~km}$; doğrultuları ise $\mathrm{K} 15^{\circ} \mathrm{D}$ ile $\mathrm{K} 70^{\circ} \mathrm{D}$ arasında değişen çizgisel gidişli çatlak ve yarıklar şeklinde gelişen kademeli yüzey deformasyonları haritalanmıştır. Yapılan analizler yüzey deformasyonu boyunca, güneydoğuda yeralan bloğun 10-40 cm arasinda düştüğüne işaret etmektedir (Şekil 8). Yerleşim alanı içerisinde haritalanan deformasyon 
yapılarının en kuzeyde olanı Bolvadin Fayı'nın güneybatıdaki devamı niteliğindedir (Şekil 6). $\mathrm{Bu}$ deformasyonlar, yer yer birkaç $\mathrm{cm}$ ile $70 \mathrm{~cm}$ arasında değişen genişlikte ve yer yer 2 metreye varan derinlikte yarıklar şeklinde izlenmektedir (Şekil 8f).

Arazi çalışmalarında yerleşim alanlarından geçen yüzey deformasyonu üzerinde yeralan bazı konutlar ve okullarda ciddi derecede hasar meydana geldiği (Şekil 9); yeraltı su ve kanalizasyon kanallarının deforme olduğu ve kırıldıkları gözlemlenmiştir. Zon içerisindeki binalar üzerinde gözlenen deformasyonlar genellikle düşen bloğa doğru eğimlenmeler, rotasyonal hareketler, duvarlarda çatlak ve yarık oluşumları şeklinde gözlenmektedir (Şekil 9).
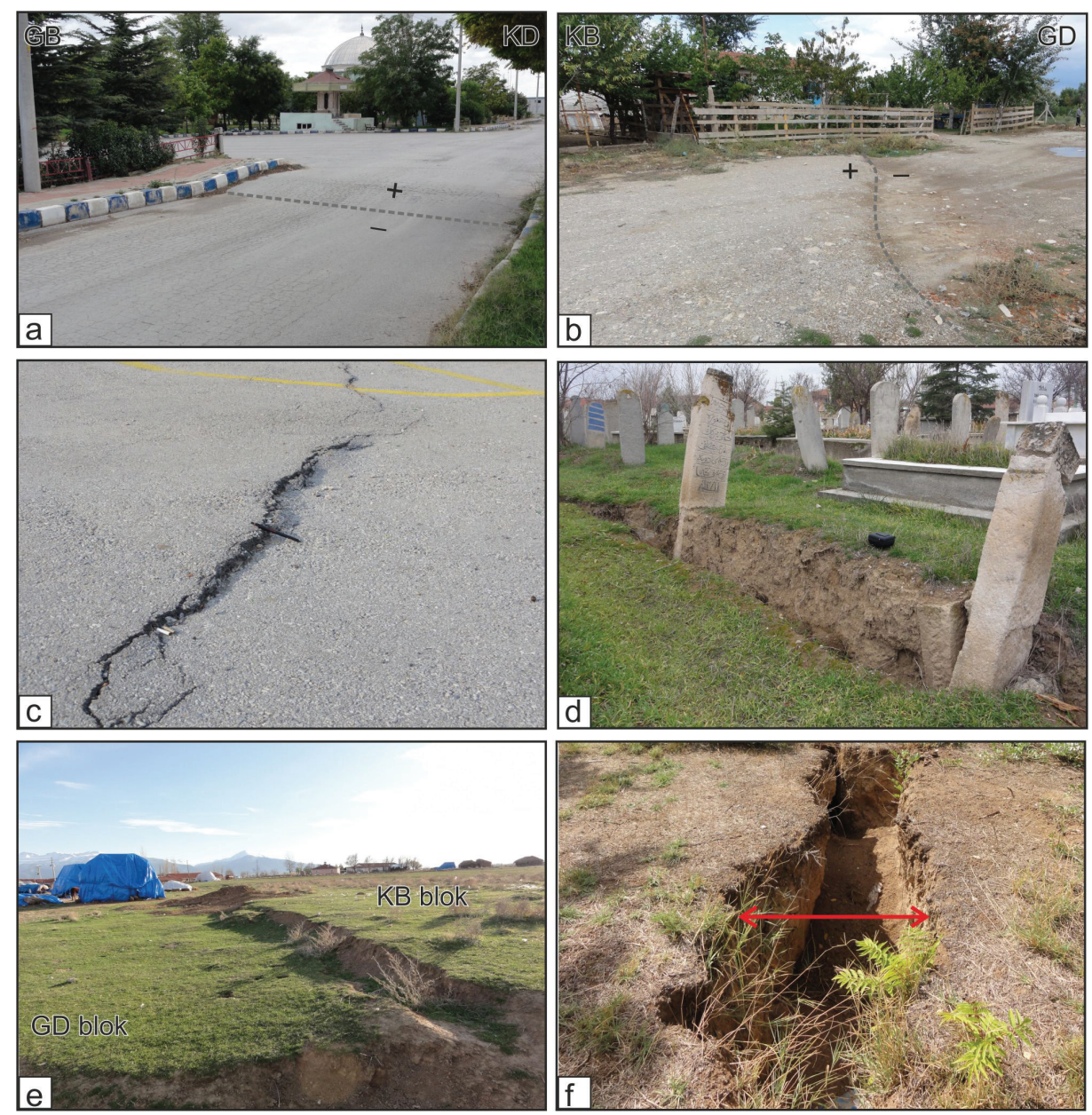

Şekil 8. Bolvadin yerleşim alanı içerisinde gözlenen yüzey deformasyonları. a-b) Akçan parkı ve yakın kuzeyinde yollar üzerinde gözlenen yüzey faylanmaları, c) Bir okulun bahçesindeki asfalt zeminde gözlenen çizgisel gidişli deformasyonlar, d) Bolvadin mezarlığında gözlenen yüzey faylanması, e) Bolvadin Abdülvahab Gazi Türbesi civarında gözlenen yüzey faylanması f) Bolvadin mezarlığı güneybatısında gözlenen yüzey yarığ 1

Figure 8. Surface deformations observed within the Bolvadin settlement area. a-b) Surface faults cutting the roads around Park Akcan. c) Linear deformations on asphalt pavement of the school garden, d) Surface faults observed within the cemetery of Bolvadin, e) Surface faults near the Bolvadin Abdülvahap Gazi Tomb, f) Earth fissures in southwest part of the cemetery of Bolvadin. 

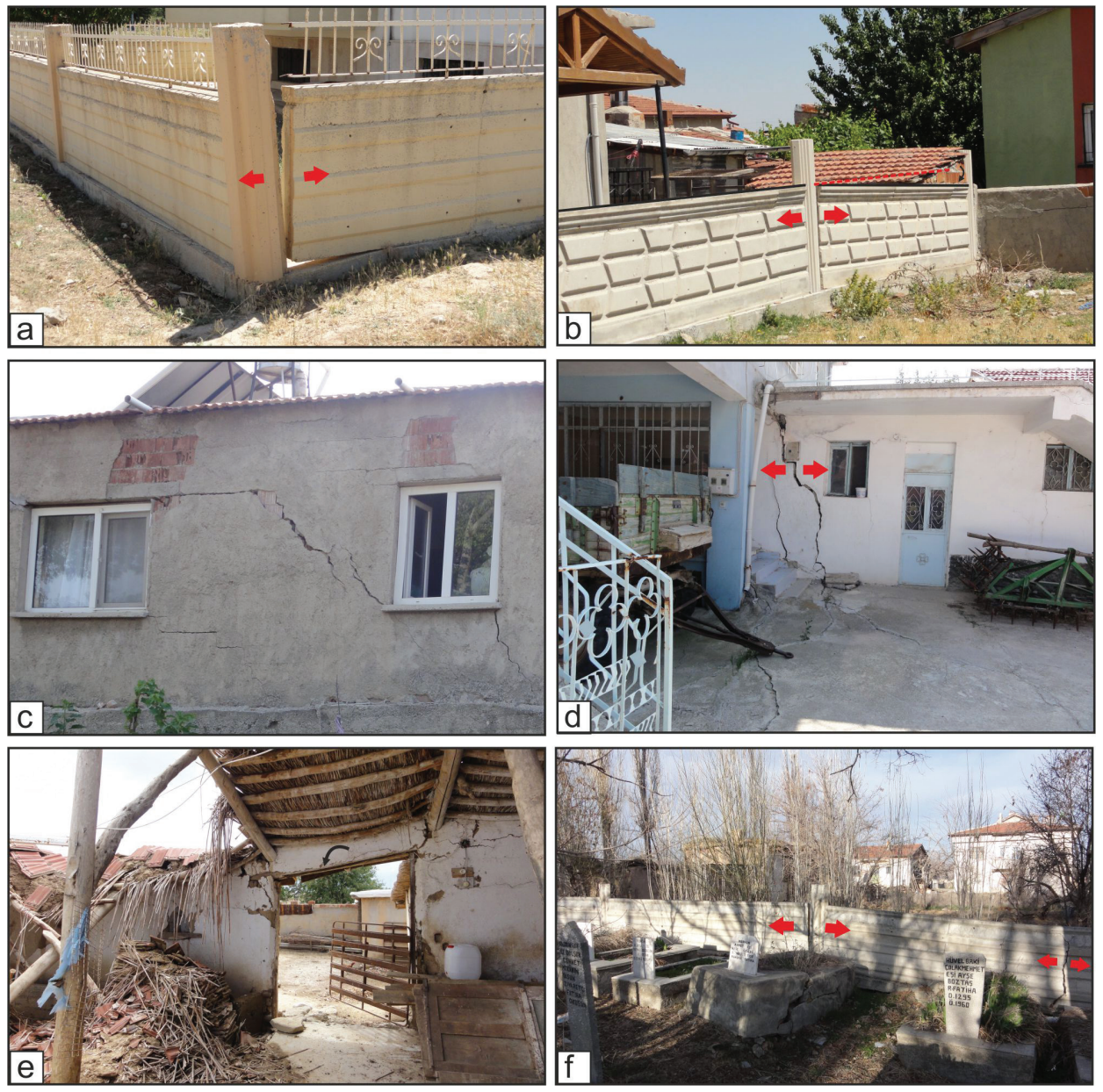

Şekil 9. Bolvadin yerleşim alanı içerisinde gözlenen deformasyonlar a-b) Akçan parkı yakınında, yüzey faylanması üzerindeki binaların bahçe duvarının düşen bloğa doğru rotasyonel hareketi sonucu oluşan açılmalar, c-d-e) Yüzey faylanması üzerinde yer alan binalarda gözlenen deformasyonlar. f) Bolvadin mezarlığı KD duvarı üzerinde gözlenen deformasyonlar

Figure 9. Deformations observed within the Bolvadin settlement area. a-b) The divergence of garden walls of some buildings located on the surface fault near the Park Akcan, $c$-d-e) Extensional cracks in some buildings located on the surface fault, f) Deformations on graves and also NE wall of the Bolvadin cemetery.

\section{Yüzey Deformasyonlarının Sınıflaması}

Asismik yüzey deformasyonları üzerinde yapılan önceki çalışmalara göre, bu deformasyonlar başlıca yüzey faylanması (surface faults) ve yüzey yarıkları (earth fissure) şeklinde sınıflanmıştır (Şekil 10) (Holzer, 1984; Pewe, 1990; Holzer ve Galloway, 2005; Pacheco-Martínez vd. 2013; Hernández-Madrigal vd. 2014). Bu çalışmalarda yapılan analizlere göre, yüzey faylanmaları ile gelişen deformasyon, su çekimi öncesinde var olan mevcut bir fayı takip ederken, yüzey yarıkları genellikle drenaj kanallarına parallel gelişirler. Yüzey faylanmalarında düşey yönde yerdeğiştirme gözlenir ve deformasyonlar derinlere doğru devam eder, ancak yüzey yarıkları boyunca düşey yönde yerdeğiştirme gözlenmez, yarıklara dik yönde açılmalar gözlenir ve bu yarıklar çok derinlere inmeden yüzeye yakın derinliklerde sönümlenirler. Her iki deformasyon tipinde de oluşan kırık ve yarıklar içerisine süzülen yüzey sularının sebep olduğu erozyonal süreçler 
(borulanma) gerçekleşir. Yüzey faylanmaları boyunca yeraltısuyunun çekilmesine bağlı olarak gelişen oturmalar sebebiyle meydana gelen düşey yerdeğiştirmelere tektonik krip de eşlik edebilir, ancak yüzey yarıkları boyunca tektonik krip gözlenmez (Çizelge 1). Deformasyon hattının uzunluğu genellikle $1 \mathrm{~km}$ 'den fazla, oluşan sarplıkları yüksekliği 0.5 metreden fazladır.

Bolvadin yerleşim alanı ve yakın çevresinde, son yıllarda gelişen kuraklığa ilave olarak havzada gereğinden fazla yapılan yeraltı su çekimleri nedeni ile yeraltı su seviyesinin son 10 y1lda yaklaşık 20 metre düştüğü bilinmektedir (Bolvadin düzlüğünde, günümüzdeki yeraltı su seviyesi ortalama 24 metredir, Özdemir, 2016). Graben kenarında yeralan Bolvadin Fayının düşen bloğunda, yeraltı su seviyesinin düşmesine bağl1 olarak zayıf konsolide olmuş alüvyal çökellerde gözlenen sıkılaşmalar ve oturmalar, Bolvadin Fayı ve havza tarafındaki gömülü sintetikleri boyunca deformasyonlara neden olmaktadır (Şekil 10). Elde edilen veriler Bolvadin'de gözlenen yüzey deformasyonlarının baskın olarak asismik yüzey faylanması şeklinde yer yer de yüzey yarıklarının geliştiğine işaret etmektedir (Şekil 10).

Çizelge 1. Bolvadin'de gözlenen güncel asismik yüzey deformasyonlarının sınıflaması (Holzer, 1984; Pewe, 1990; Holzer ve Galloway, 2005; Pacheco-Martínez vd. 2013; Hernández-Madrigal vd. 2014, Özkaymak vd. 2015).

Table 1. Classification of recent aseismic surface deformations in Bolvadin (Holzer, 1984; Pewe, 1990; Holzer and Galloway, 2005; Pacheco-Martínez et al., 2013; Hernández-Madrigal et al., 2014, Özkaymak et al. 2015).

\begin{tabular}{|l|l|}
\hline \multicolumn{2}{|c|}{ Bolvadin'de Gözlenen Güncel Asismik Yüzey Deformasyonları } \\
\hline Yüzey Faylanması (Surface Faults) & Yüzey Yarıkları (Earth Fissures) \\
\hline Deformasyon, varolan bir fayı takip eder & Derinlere inmezler \\
\hline Düşey yönde yerdeğiştirme gözlenir & Genellikle drenajlara paralel gelişirler \\
\hline Tektonik krip gelişebilir & Düşey yönde bir yerdeğiştirme gözlenmez \\
\hline Sarplıklar genellikle 0,5 m'den fazladır & Yarıklara dik yönde açılmalar gözlenir \\
\hline Deformasyonun uzunluğu genellikle 1 km'den fazladır & Tektonik krip gözlenmez \\
\hline Borulanma gerçekleşebilir & Borulanma gerçekleşebilir \\
\hline
\end{tabular}

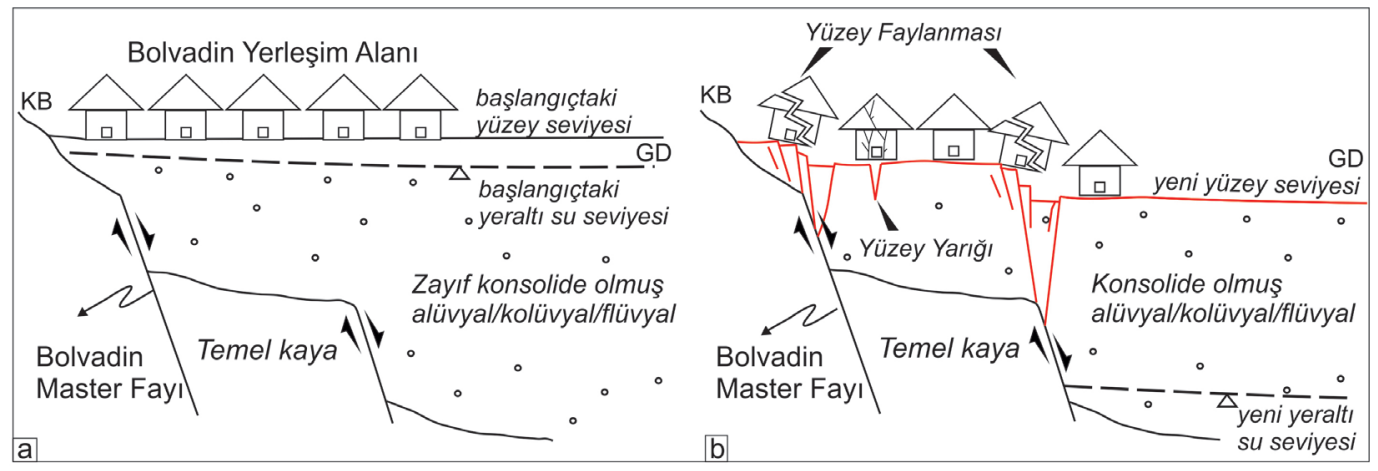

Şekil 10. Bolvadin yerleşim alanında gözlenen güncel deformasyonlarının nedenlerinin kökensel açıdan yorumlanmasını gösteren ölçeksiz ve şematik jeolojik kesitler, a) yeraltı suyu çekimi öncesi b) yeraltı suyu çekimi sonrası gelişen yapılar (Carpenter, 1999 ve Pacheco-Martínez vd. 2013'den değiştirilmiştir).

Figure 10. Geological cross sections (not to scale) showing the interpretations of origins and causes of the recent aseismic surface deformations in Bolvadin settlement area. a) Initial condition, b) formation of surface faults and earth fissures due to groundwater withdrawal subsidence (compiled from Carpenter, 1999 ve Pacheco-Martinez et al. 2013). 


\section{YÜZEY DEFORMASYONLARININ JEODEZIK ANALIZLERİ}

Afyon Akşehir Grabeni'nin güncel tektonik hareketlerini incelemek için bölgeye 20 noktalı bir GNSS ağı kurulmuştur. Bu kapsamda, 2012-2015 y1lları arasında bu noktalarda yılda 2-3 gün ve 8 er saatlik tekrarlı ölçüler olmak üzere 3 kampanya GNSS ölçüsü yapılmıştır. GNSS verilerinin değerlendirilmesi, MIT tarafından geliştirilen GAMIT (GPS Analysis Massachussets Institute of Technology)/GLOBK (GLOBal Kalman) yazılım takımı kullanılarak yapılmıştır. Bu noktalardan Bolvadin Fayı'nın düşen bloğu üzerinde kurulu AKTC noktasında ilk 3 kampanya ölçüsünde düşey yönde deformasyon tespit edilmiştir. Düşey deformasyonun olduğu AKTC noktası yüzey deformasyonlarının olduğu bölgeye çok yakındır. $\mathrm{Bu}$ deformasyonların yıllık davranışını incelemek için 2015 y1lı ocak ayında bu noktaya sabit GNSS istasyonu kurularak ölçü toplanmaya başlanmıştır (Şekil 11). Güneş panelleri ile desteklenen istasyonda yaklaşık iki yıldır veri toplanmıştır. 3.5 y1llık zaman zarfinda yaklaşı $25 \mathrm{~cm}$ deformasyon meydana gelmiştir. Deformasyon hızı $7,1 \mathrm{~cm} /$ y1l olarak hesaplanmıştır. Bölgede devam eden çalışmalar kapsamında, GNSS ölçüsü, Nivelman ve SAR tekniklerinin birlikte kullanılmasıyla düşeyde ve yatayda oluşan deformasyonlar takip edilecek ve bu deformasyonların, bölgenin güncel tektonik hareketleri içerisindeki yeri yorumlanacaktır.

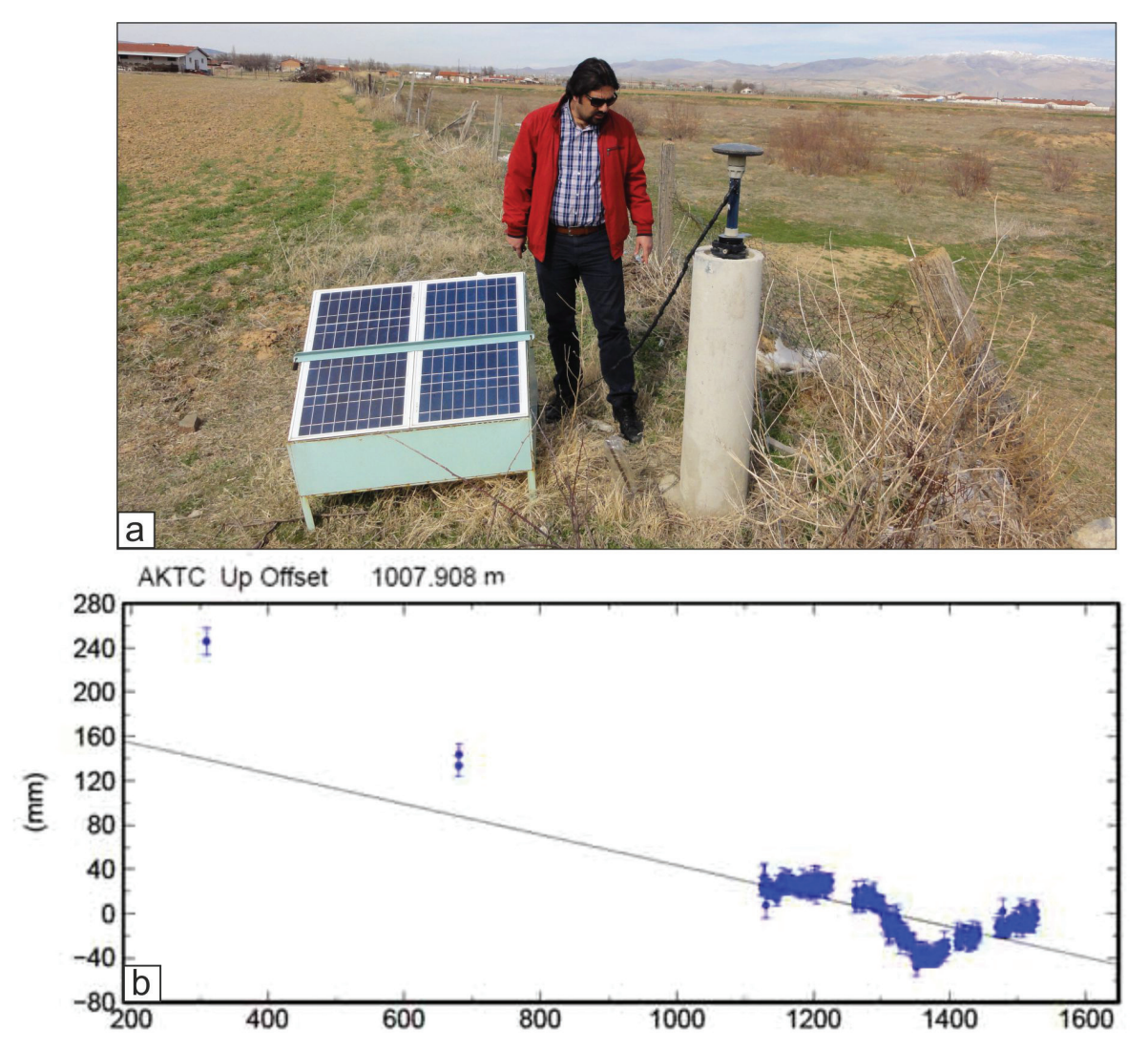

Şekil 11. a) Güneş panelleri ile desteklenen sabit GNSS istasyonu (AKTC istasyonu), b) AKTC istasyonunda ölçülen düşey deformasyonu gösteren diyagram.

Figure 11. GNSS Permanent Station supported by solar panel (AKTC station), b) Diagram showing the vertical deformation measured by AKTC station. 


\section{TARTIŞMA VE SONUÇLAR}

Asismik yüzey deformasyonları, gravitasyonal kütle hareketleri, mağmatik kökenli faaliyetler, karstik kökenli oluşumlar, yeraltı madenciliği ilişkili çökmeler, bataklık drenajı, tünel gibi yeraltı mühendislik faaliyetleri ile de gelişebilmektedir. Ancak Batı Anadolu'da son 20 yıldır gözlenen çizgisel gidişli asismik yüzey deformasyonları üzerinde yapılan çalışmalar bu deformasyonların graben kenar fayları üzerinde baskın olarak yüzey faylanması şeklinde geliştiğine işaret etmektedir (Gürsoy vd. 1997; Demirtaş vd. 2008a,b; Koca vd. 2011; Özkaymak vd. 2014 ve 2015). Bununla beraber, bu çalışmalarda, deformasyon alanlarında yeraltı su seviyelerinde kuraklığa ve aşırı su çekimine bağlı olarak önemli miktarlarda düşmeler gerçekleştiğinden de bahsedilmektedir. Yeraltı su seviyesinin düşmesine bağlı olarak konsolide olmamış yada az konsolide olmuş alüvyal çökellerin yenilmesi ile bölgede yeralan faylar boyunca asismik yüzey faylanması şeklinde deformasyonların meydana geldiği uluslararası birçok çalışmada belirtilmektedir (Holzer, 1980, 1984; Pewe, 1990; Holzer ve Galloway, 2005; Hernández-Madrigal vd. 2014; Pacheco-Martínez vd. 2013). Bolvadin bölgesinde tarafimızdan yapılan arazi çalışmaları, yıkııı deprem olmaksızın, uzunlukları 300 metre ile $2 \mathrm{~km}$; doğrultuları ise $\mathrm{K} 15^{\circ} \mathrm{D}$ ile $\mathrm{K} 70^{\circ} \mathrm{D}$ arasında değişen çizgisel gidişli baskın olarak yüzey faylanması ile yer yer yüzey yarıkları şeklinde gelişen asismik yüzey deformasyonlarının varlığını ortaya çıkarmıştır. Bolvadin yerleşim alanı içerisinde haritalanan bu deformasyon hatlarından en kuzeyde olanı Bolvadin Fayı'nın güneybatıdaki devamı niteliğindedir. Yapılan analizler yüzey deformasyonu boyunca, güneydoğuda yer alan bloğun ortalama 10-40 cm arasında düştügüne işaret etmektedir.

Batı Anadolu Genişleme Bölgesinde, son 1020 yılda yıkıcı deprem olmaksızın oluşmuş ve oluşmaya devam eden yüzey deformasyonlarının belirgin örneklerinden bir diğeri, Gediz
Grabeni'nin güneydoğu ucunda yer alan Sarıgöl yerleşim alanında gözlenmiştir. $\mathrm{Bu}$ alanda yerleşim alanından geçen Sarıgöl Fayı boyunca kanallarda, asfalt yollarda ve evlerin duvarlarında 1.00-1.25 metre arasında düşey yer değiştirmeler şeklinde yüzey deformasyonlar1 (K50-80 ${ }^{\circ} \mathrm{B}$ doğrultulu) meydana gelmiştir (Koca vd. 2011). Bu deformasyonlar Koca vd. (2011) tarafindan detaylı yeraltı (karotlu sondaj verileri) ve yüzey (jeolojik ve jeomorfolojik) verileri ile yorumlanmıştır. Araştırmacılar, Sarıgöl ve çevresinde yeraltı su seviyesinin son onyıl içerisinde yaklaşı 20 metre düşüşüne bağlı olarak, killi katmanlarda meydana gelen aşırı konsolidasyon olayı ve bunun sonucunda gelişen oturma miktarlarını sondaj karot verileri ve bunların konsolidasyon deneyleri ile hesaplamışlardır. Maksimum oturma miktarının, yüzeyde ölçülen düşey yerdeğiştirmeyi karşılamadığ1; arada kalan 22,5 cm'lik oturmaların nedeninin, olasılıkla, sismik aktiviteye $(\mathrm{M}<4.0)$ bağlı olarak Sarıöl Fayı boyunca meydana gelen ya da fay yüzeyi boyunca düşen bloğun rotasyonel hareketine bağlı gelişen yerdeğiştirmeler olabileceğini ileri sürmüşlerdir. Ayrıca, Afet İşleri Genel Müdürlüğü tarafından Sarı̈öl bölgesinde gelişen deformasyonların analiz edildiği 17.04.2008 tarihli jeolojik etüd raporunda, bölgede meydana gelen olayların tektonik krip özelliği taşıdığından ve 20-40 cm'lik oturmaların tektonik krip ile meydana geldiği belirtilmişir (Demirtaş vd. 2008b). Sonuç olarak, Sarıgöl bölgesinde yapılan çalışmalar, bu bölgedeki asismik yüzey faylanmaları ile meydana gelen düşey yerdeğiştirmelerin yeraltı suyu düşüşüne bağlı gelişen oturmalar ile birlikte tektonik krip ve sismik etkinlikler ile de açıklandığına işaret etmektedir. Koca vd. (2011)'e göre 2000 ile 2010 y1lları arasındaki 10 y1llı süreçte Sarı̈öl Fayı boyunca 0.68 ile 0.85 metre düşey yerdeğiştirmeler ölçülmüştür. Bu durumda Sarı̈öl bölgesi için düşey yerdeğiştirme hızı 6 ile $8,5 \mathrm{~cm} / \mathrm{y} 1 \mathrm{l}$ arasında hesaplanmıştır. Sarıgöl bölgesinde yapılan GPS ve Ps-InSAR yöntemleri 
ile elde edilen sonuçlara göre ise, deformasyonun h1z1 $10 \mathrm{~cm} /$ y1ldır (Poyraz vd. 2015). Bolvadin bölgesinde gözlenen sarplıklardaki jeomorfolojik ölçümlerimize göre, 4 yıl içerisinde 0,26 ile 0,38 metre düşey yerdeğiştirmelerin gerçekleştiği tespit edilmiştir. Elde edilen veriler Bolvadin Fayı boyunca düşey yerdeğiştirme hızının 6,5 ile $9,5 \mathrm{~cm} / \mathrm{y} 1 \mathrm{l}$ olduğunu göstermektedir. Bölgedeki GNSS istasyonlarından topladığımız verilere göre ise, düşey yerdeğiştirme hızı 7,1 cm/y1l olarak hesaplanmıştır. Bu değerler Sarıgöl bölgesinde ölçülen değerler ile uyumludur. Bunun yanında, Batı Anadoludaki ölçümler, Amerika'da benzer deformasyonların gözlendiği alanlarda elde edilen verilere ve ölçülen değerlere (6 cm/yıla kadar) (Holzer, 1984) yakındır.

Bolvadin bölgesinde, yeraltı su seviyelerinin kuraklık ve aşırı su çekimine bağlı olarak orantısız bir şekilde düşmesi göz önüne alındığında, fayın tavan bloğunda yeralan az konsolide olmuş alüvyal çökellerde meydana gelen sıkışma ve oturmaların Bolvadin Fayı boyunca meydana gelen deformasyon ve düşey yönde yerdeğiştirmelerin önemli bir bölümünün yeraltı su seviyesinin düşmesiyle ilgili olduğu açıktır. Ancak, (1) Bolvadin Fayının heran deprem üretebilecek diri bir fay olduğu (Emre vd. 2011), (2) bölgede son yıllarda meydana gelen yüzey kırığı oluşturan yıkıcı depremlerin (3 Şubat 2002 Çay depremleri $\left.M_{w}: 6.3-6.0\right)$ ve mevcut mikro-sismik etkinliğin varlığı, (3) bu sismik etkinliğe bağlı olarak gelişen aktif çöküntü alanının kuzey kenarının Bolvadin Fayı ile kontrol edildiği, (4) Bölgedeki drenaj sisteminin, iklim olaylarının yanısıra, bölgede yeralan aktif faylar ve yoğun sismik etkinlik ile kontrol ettiği, (5) benzer deformasyon özelliklerinin gözlendiği Sarıgöl bölgesinde yeraltı su seviyesinin düşmesine bağlı oturmalara sismik etkinliklerin ve tektonik krip olayının da eşlik ettiği (Koca vd. 2011; Demirtaş vd. 2008b) göz önüne alındığında, Bolvadin bölgesinde gelişmekte olan yüzey deformasyonları sadece yeraltı suyunun düşmesine bağlı gelişen konsolidasyon oturmaları ile ilişkili olmayabileceği sonucu ortaya çıkmaktadır. Bolvadin bölgesinde gelişmekte olan asismik yüzey deformasyonlarının oluşum ve kökensel analizinde tektonizmanın bir rolü olup olmadığının anlaşılması bakımından Bolvadin Master Fayı üzerinde hendek tabanlı paleosismolojik çalışmaları ve Bolvadin Fayının düşen bloğunda yer alan sedimanlar üzerinde konsolidasyon testlerinin yapılması gerekmektedir.

\section{KATKI BELIRTME}

$\mathrm{Bu}$ çalışma, Afyon Kocatepe Üniversitesi BAP 14.MUH.01 ve 12.TEMATIKK.02 numaralı projeler kapsamında desteklenmiştir. Bu çalışmada sunulan ön bulgular ile TÜBİTAK-115Y246 numaralı proje olarak kabul edilmiştir. Yazarlar, makaleye yapıcı katkı sağlayan Süha Özden (Çanakkale Onsekiz Mart Üniversitesi) ve ismini açıklamayan diğer hakeme teşekkürü bir borç bilir.

\section{EXTENDED SUMMARY}

In recent years, some surface deformations that have been formed without earthquake failure are observed along the active margin faults of Quaternary grabens in WAEP(Figure 1). One of the two prominent examples is located on the Sartgöl settlement area in Gediz Graben, while other is on the Bolvadin settlement area in Afyon Akssehir Graben (AAG). AAG represents the southeastern part of Akşehir-Simav Fault System (ASFS) which is one of the most important seismogenic zones within West Anatolian Extensional Province (WAEP). The historical and instrumental earthquake records suggest the existence of a large number of earthquakes that created surface ruptures in this system. Bolvadin city and its surroundings are located in the middle of the $A A G$ which is an approximately $130 \mathrm{~km}$ long and $N W$ SE trending active depression area (Figure 2). Some linear aseismic surface deformations that starts on the southwestern side of the town and 
can be followed until the northwestern side have been observed since last 4 years in the Bolvadin settlement area. In this study, we focused on the geologic, geomorphologic and geodesic analyses of the aseismic surface deformations in Bolvadin (AAG, Afyon) and compared the similarities of the aseismic surface deformations observed in Sarlgöl and Bolvadin in terms of their origin and formation mechanism.

The latest seismic activities in the $A A G$ are evidenced by the 03 February 2002 Çay (Afyon) earthquakes with Mw: 6.3 and Mw 6.0 in size. These earthquakes that caused surface ruptures in Maltepe and Çay settlements and nearby areas in the western parts of the Sultandağl Fault, are the final members of the earthquake migration from southeast to northwest, which began in southeastern part of the Sultandăg Fault in 1921, and progressed northwestward in 1946 and 2000 (Figure 5 and 6). During the field studies in Bolvadin area, progressive aseismic surface deformations, such as linear surface faults and earth fissures whose length varies between 300 meters and 2 kilometers and strike varies between $N 15^{\circ} \mathrm{E}$ and $N 70^{\circ} \mathrm{E}$ were mapped. Besides this, quantitative and morphological analysis indicate that the southeastern block is a downdropped block and vertical displacements along the deformation zone are varies between $10-40 \mathrm{~cm}$. The northernmost one of the surface deformations mapped in the settlement area of Bolvadin have the characteristics of the southwestern continuation of Bolvadin Fault which is a NE-SW trending and SE-dipping dip-slip normal fault. Field-based geological studies and kinematic analyses along the active Bolvadin Fault suggest that the NE-SW trending normal faulting is consistent with a NWSE extensional stress regime (Figure 7).

The morphometric analysis using GNSS measurement and Levelling techniques yield the deformation rate (the vertical displacement) of $7.1 \mathrm{~cm} / y$ for the surface deformations on Bolvadin Fault, which are similar to deformation rate of
$10 \mathrm{~cm} / y$ calculated by using GPS and In-SAR techniques for Sarigöl area in Gediz Graben (Poyraz et al. 2015). Besides this, deformation rates of aseismic surface deformations in WAEP are in accordance with the deformation rates calculated along the similar aseismic surface deformations in USA (up to $6 \mathrm{~cm} / \mathrm{y}$, Holzer, 1984).

It is clear that the role of the groundwater withdrawal from unconsolidated sediments due to the effect of groundwater pumping by human activities and natural drought is an important agent for that aseismic surface failure. However, some knowledge about the region given below are associated with the effect of active tectonics on aseismic surface deformation. (1) Bolvadin Fault is an active fault (Emre et al. 2011) and recent aseismic surface deformations follow the surface trace of Bolvadin Master Fault, (2) Recently, the surface ruptured destructive earthquakes cause depression along the south of Bolvadin in $A A G$ (3 February 2002 Çay earthquakes, $M_{w}: 6.3-6.0$ ) and there is an intensive micro-seismic activity in the region, (3) The northern border of that depression area is controlled by Bolvadin Fault, (4) the drainage system is also controlled by active faults and seismic activities in the region, (5) Besides the withdrawal of underground fluids and consolidation of sediments, it is suggested that tectonic creep and micro-seismic activities also cause to surface deformation on Sarigöl Fault which is an active dip-slip normal fault just as the Bolvadin Fault (Koca vd., 2011; Demirtas $v d ., 2008 b)$. All of these outcomes indicate that the origin and formation mechanism of the aseismic surface deformation in Bolvadin may not be explained solely by the groundwater withdrawal from unconsolidated sediments. For the future studies, in order to determine the consolidation characteristics of sediments, consolidation tests should be performed on the hanging wall sediments of Bolvadin Fault. Besides this, trenchbased palaeoseismological studies should also be performed along the Bolvadin Fault to document 
evidence for the Holocene activities and estimate the long-term slip-rates or earthquake recurrence intervals.

\section{DEĞINILEN BELGELER}

Akyüz, S., Uçarkuş, G., Şatır, D., Dikbaş, A. ve Kozac1, Ö., 2006. 3 Şubat 2002 Çay depreminde meydana gelen yüzey kırığ 1 üzerinde paleosismolojik araştırmalar. Yerbilimleri, 27 (1), 41-52.

Aydar, E., Bayhan, H. ve Gourgaud, A., 2003. The lamprophyres of Afyon Stratovolcano, Western Anatolia, Turkey: Description and genesis. C.R. Geoscience, 335, 279-288.

Blumenthal, M., 1963. Le systeme structural du Taurus sud-Anatolien. In Livre a memoire du Proffesseur P. Fallot. Memoire de la Societe Geologique de France, 2, 611-662.

Bozkurt, E. ve Oberhansl1, R., 2001. Menderes Massif (Western Turkey): structural, metamorphic and magmatic evolution - a synthesis. International Journal Earth Sciences, 89, 679-708.

Carpenter, M.C., 1999. South-Central Arizona. Earth fissures and subsidence complicate development of desert water resources. In: Galloway, D., Jones, D.R., Ingebritsen, S.E. (Eds.), Land Subsidence in the United States. U.S. Geological Survey. Circular, 1182. U.S. Department of the Interior, Reston, Virginia, U.S.A.

Çevikbaş A., Ercan, T. ve Metin, S., 1988. Geology and Regional Distribution of Neogene Volcanics Between Afyon-Şuhut. Journal of Pure and Applied Sciences, METU, 21 (1-3), 479-499.

Demirtaş, R., Iravul, Y., ve Yaman M. 2002. 3 Şubat 2002 Eber ve Çay depremleri ön raporu. Jeoloji Mühendisliği Haber Bülteni, (1 - 2), 58 - 63 .

Demirtaş, R., Ercan, S., Demir, B. ve Aktan., M., 2008a. Ege Çöküntü Bölgesi'nde Alüvyal Havzalarda Son 20 Yılda Oluşmuş Yüzey Deformasyonlarının Oluşum Mekanizması. ATAG 12 Bildiri Özleri Kitab1, 42-44.

Demirtaş, R., Yavuz, M.A. ve Şahin, B. 2008b. Manisa ili, Sarıgöl ilçesi İmar Planı Sınırları içerisinde geçen Gediz Çöküntüsüne ait fay zonunun Paleosismolojik ve Yüzey Faylanması Tehlike
Zonu Açısından Değerlendirilmesi. Afet İşleri Genel Müdürlüğü Raporu. 17s (yayınlanmamış).

Emre, Ö., Duman, T.Y., Doğan, A., Özalp, S., Tokay, F. ve Kuşcu, İ., 2003. Surface Faulting Associated with the Sultandağı Earthquake (Mw 6.5) of 3 February 2002, Southwestern Turkey. Seismological Research Letters 74 (4), 382-392.

Emre, Ö., Duman, T. Y., Özalp, S., Olgun, Ş. ve Elmacı, H., 2011. 1:250.000 scale active fault map series of Turkey, Afyon (NJ 36-5) Quadrangle. Serial number: 16, General Directorate of Mineral Research and Exploration, Ankara, Turkey.

EMSC (European-Mediterranean Seismological Centre), 2016. http://www.emsc-csem.org, 3 June 2016.

Ergin, K., Güçlü, U. ve Uz, Z., 1967. Türkiye ve Civarının Deprem Kataloğu (MS. 11-1964).

İstanbul: İstanbul Teknik Üniversitesi Maden Fakültesi Arz Fiziği Enstitüsü yayınları, No 28.

Hernández-Madrigal, V. M., Muñiz-Jauregui, J. A., Garduño-Monroy, V. H, Flores-Lázaro, N. ve Figueroa-Miranda, S. 2014. Depreciation factor equation to evaluate the economic losses from ground failure due to subsidence related to groundwater withdrawal. Natural Science, 6 (3), 108-113.

Holzer, T.L., 1978. Results and Interpretation of Exploratory Drilling Near the Picacho Fault, South-Central Arizona: U.S. Geological Survey Open- File Report 78-1016, 17 p.

Holzer, T.L., 1980. Faulting Caused by Ground-Water Level Declines, San Joaquin Valley, California. Water Resources Research, 16 (6), 1065- 1070.

Holzer, T.L., 1984. Ground failure induced by groundwater withdrawal from unconsolidated sediment. In: Holzer Holzer, T.H., Ed., ManInduced Land Subsidence, VI. Geological Society of America. Reviews in Engineering Geology, Colorado, 67-105.

Holzer, T.L. ve Galloway, D.L., 2005. Impacts of land subsidence caused by withdrawal of underground fluids in the United States. Geological Society of America, Reviews in Engineering Geology, 16, 87-99. 
Gürsoy, H., Temiz, H., Tatar, O. ve Barka, A., 1997. Gediz grabeni güney kenarındaki güncel deformasyon verileri. II. İzmir ve Çevresinin Jeoteknik ve Deprem Sorunları Sempozyumu, Bildiri Özetleri, s.14.

KANDİLLİ (Kandilli Rasathanesi ve Deprem Araştırma Enstitüsü), 2011. http://www.koeri. boun.edu.tr/, 3 June 2016.

Kaymakc1, N., 2006. Kinematic development and paleostress analysis of the Denizli Basin (Western Turkey): Implications of spatial variation of relative paleostress magnitudes and orientations. Journal of Asian Earth Sciences, 27, 207-222.

Kibici, Y., Dinç, D., ve Uçar, A., 2012. Afyonkarahisar Yöresi Volkanik Kayaçlarının Mineralojik ve Petrografik Özellikleri. Dumlupınar Ü. Fen Bilimleri Enstitüsü Dergisi, 29, 53-70.

Koca, M. Y., Sözbilir, H. ve Uzel, B., 2011. Sarıgöl Fay Zonu Boyunca Meydana Gelen Deformasyonların Nedenleri Üzerine bir araştırma. Jeoloji Mühendisliği Dergisi 35 (2), 151-173.

Koçyiğit, A., 1984. Güneybatı Türkiye ve yakın dolayında levha içi yeni tektonik gelişim. Türkiye Jeoloji Kurumu Bülteni, 27 (1), 1 - 15.

Koçyiğit, A., Ünay, E. ve Saraç, G. 2000. Episodic graben formation and extensional neotectonic regime in west Central Anatolia and the Isparta Angle: a case study in the Akşehir-Afyon Graben, Turkey. Geological Society of London Special Publication, 173, 405-421.

Koçyiğit, A., Bozkurt, E., Kaymakçı, N. ve Şaroğlu, F., 2002. 3 Şubat 2002 Çay (Afyon) Depreminin Kaynağı ve Ağır Hasarın Nedenleri: Akșehir Fay Zonu, ODTÜ Tektonik Araştırma Birimi Ön Raporu, 19 s.

Koçyiğit, A. ve Özacar, A. 2003. Extensional neotectonic regime through the NE edge of outer Isparta Angle, SW Turkey: new field and seismic data. Turkish Journal of Earth Sciences 12, 67-90.

Okay, A.I., Satır, M., Maluski, H., Siyako, M., Monie, P., Metzger, R. ve Akyüz S., 1996. Paleo- and NeoTethyan events in northwest Turkey: geological and geochronological constraints. in Tectonics of Asia (ed. A. Yin ve M. Harrison), Cambridge University Press, 420-441.
Okay, A.I. ve Tüysüz, O., 1999. Tethyan sutures of northern Turkey. In «The Mediterranean Basins: Tertiary extension within the Alpine orogen» (eds. B. Durand, L. Jolivet, F. Horváth and M. Séranne). Geological Society, London, Special Publication $156,475-515$.

Özdemir, T., 2016. Kişisel Görüşme. Bolvadin, Afyon, Türkiye.

Özden, S., Kavak, K.Ş., Koçbulut, F., Över, S. ve Temiz, H., 2002. 3 Şubat 2002 Çay (Afyon) Depremleri, Türkiye Jeoloji Bülteni, 45 (2), 49-56.

Özkaymak, Ç., 2015. Tectonic analysis of the Honaz Fault (western Anatolia) using geomorphic indices and the regional implications. Geodinamica Acta, 27 (2-3), 110-129.

Özkaymak, Ç., Sözbilir, H. ve Uzel B., 2013. NeogeneQuaternary evolution of the Manisa Basin: Evidence for variation in the stress pattern of the İzmir-Balıkesir Transfer Zone, western Anatolia. Journal of Geodynamics Special issue: Tethyan Evolution, Anatolia. 65, 117-135

Özkaymak, C.., Yıldız, A., Sarıkaya, H., Başaran, C., Dumlupınar, İ., Akman, İ., 2014. Bolvadin Fayı boyunca meydana gelen yüzey deformasyonları, Batı Anadolu-Türkiye. Aktif Tektonik Araştırma Grubu Çalıştayı Onsekizinci Çalıştayı (ATAG18), Bildiri Özleri Kitabı, s. 52.

Özkaymak, Ç., Sözbilir, H., Tiryakioğlu, İ., Baybura, T., 2015. Sarıöl (Gediz Grabeni, Manisa) ile Bolvadin'de (Afyon-Akşehir Grabeni, Afyon) Gözlenen Yüzey Deformasyonlarının Oluşum ve Kökensel Açıdan Karşılaştırılması. TMMOB Jeoloji Mühendisleri Odasi 68. Türkiye Jeoloji Kurultayı Bildiri Özleri Kitabı, s. 464-465.

Pacheco-Martínez, J., Hernandez-Marín M., Burbey., T. J., González-Cervantes, N., Ortíz-Lozano, J.Á., Zermeño-De-Leon, M.E. ve Solís-Pinto, A., 2013. Land subsidence and ground failure associated to groundwater exploitation in the Aguascalientes Valley, México. Engineering Geology 164, 172186.

Pankratz, L. W., Ackermann, H. D., ve Jachens, R. C., 1978. Results and Interpretation of Geophysical Studies Near the Picacho Fault, South-Central Arizona: U.S. Geological Survey Open-File Report 78-1106, $17 \mathrm{p}$. 
Pewe, 1990. Land subsidence and earth-fissure formation caused by groundwater withdrawal in Arizona; A review. Groundwater Geomorphology The role of subsurface water in Earth-surface processes and Landforms, edited by Charles G. Higgins, Donald Robert Coates, Geological Society of America pub. p. 252.

Pınar, N. ve Lahn, E., 1952. Türkiye Depremleri İzahlı Kataloğu. Bayındırlık Bakanlığı, Yapı ve İmar İşleri Reisliği, No. 6, Ankara.

Poyraz, F., Tatar, O., Hastaoğlu, K.Ö., Tiryakioğlu, İ., Gürsoy Ö., Koçbulut F., Türka, T., Demirel, M., Duman, H., Ciğer, A.F. ve Güle, D., 2015. Gediz Grabeninin Doğu Kesimindeki Güncel Tektonik Hareketlerin GPS ve Ps-InSAR Yöntemleri Kullanılarak Belirlenmesi; İlk Sonuçlar. Harita Teknolojileri Elektronik Dergisi 7(1), 17-28.

Tiryakioğlu, İ., Baybura, T., Özkaymak, Ç., Sözbilir, H., Sandıkçıŏlu, A., Erdoğan, S., Yılmaz, İ., Uysal, M., Yılmaz, M., Yıldız, A., Dereli, M.A., Yalçın, M., Dumlupınar, İ., M., Yalım, H., Ertuğrul, O., 2015. Sultandağı Fayı Batı Kısmı Fay Aktivitelerinin Multidisipliner Çalışmalarla Belirlenmesi. Harita Teknolojileri Elektronik Dergisi, 7(1), 7-16.
Turan, N., 2002.Geological map of Turkey in 1:500.000 scale: Ankara sheet.Publication of Mineral Research and Explaniton Direction of Turkey (MTA), Ankara.

Ulusay, R., Aydan, Ö., Erken, A., Tuncay, E., Kumsar, H. ve Kaya, Z., 2004. An overview of geotechnical aspects of the $\mathrm{C}$ ay-Eber (Turkey) earthquake. Engineering Geology 73, 51-70.

Van Siclen, D. C., 1967. The Houston Fault Problem, in Proceedings, American Institute of Professional Geologists, Texas Section, Annual Meeting, 3rd, Dallas, p. 9-31.

Yürür, T., Köse, O., Demirbağ, H., Özkaymak, Ç. ve Selçuk, L. 2003. Could the coseismic fractures of a lake ice reflect the earthquake mechanism? (Afyon earthquakes of 2 March 2002, Central Anatolia, Turkey). Geodinamica Acta 16, 83-87. 